\title{
Dungeness Crab Dredging- Entrainment Studies in the Lower Columbia River, 2002 to 2004: Loss Projections, Salinity Model, and Scenario Analysis
}

\author{
W. H. Pearson \\ G. D. Williams \\ J. R. Skalski
}

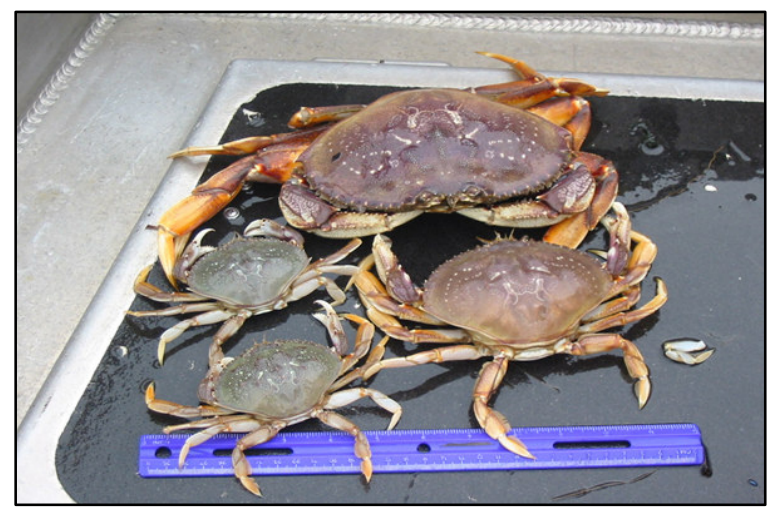

January 2005

Prepared for

貲

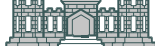

U.S. Army Corps of Engineers

Portland District

under a Related Services Agreement

with the U.S. Department of Energy

under Contract DE-AC05-76RL01830

\section{Pacific Northwest \\ National Laboratory \\ Operated by Battelle for the \\ U.S. Department of Energy}




\title{
DISCLAIMER
}

This report was prepared as an account of work sponsored by an agency of the United States Government. Neither the United States Government nor any agency thereof, nor Battelle Memorial Institute, nor any of their employees, makes any warranty, express or implied, or assumes any legal liability or responsibility for the accuracy, completeness, or usefulness of any information, apparatus, product, or process disclosed, or represents that its use would not infringe privately owned rights. Reference herein to any specific commercial product, process, or service by trade name, trademark, manufacturer, or otherwise does not necessarily constitute or imply its endorsement, recommendation, or favoring by the United States Government or any agency thereof, or Battelle Memorial Institute. The views and opinions of authors expressed herein do not necessarily state or reflect those of the United States Government or any agency thereof.

\author{
PACIFIC NORTHWEST NATIONAL LABORATORY \\ operated by \\ BATTELLE \\ for the \\ UNITED STATES DEPARTMENT OF ENERGY \\ under Contract DE-AC05-76RL01830
}

Printed in the United States of America

Available to DOE and DOE contractors from the

Office of Scientific and Technical Information,

P.O. Box 62, Oak Ridge, TN 37831-0062;

ph: (865) 576-8401

fax: (865) 576-5728

email: reports@adonis.osti.gov

\author{
Available to the public from the National Technical Information Service, \\ U.S. Department of Commerce, 5285 Port Royal Rd., Springfield, VA 22161 \\ ph: (800) 553-6847 \\ fax: (703) 605-6900 \\ email: orders@ntis.fedworld.gov \\ online ordering: http://www.ntis.gov/ordering.htm
}

This document was printed on recycled paper.

$(1 / 03)$ 


\title{
Dungeness Crab Dredging-Entrainment Studies in the Lower Columbia River, 2002 to 2004: Loss Projections, Salinity Model, and Scenario Analysis
}

\author{
W. H. Pearson \\ G. D. Williams \\ Pacific Northwest National Laboratory \\ Marine Sciences Laboratory \\ Sequim, Washington \\ J. R. Skalski \\ Columbia Basin Research \\ School of Aquatic and Fishery Sciences \\ University of Washington \\ Seattle, Washington
}

January 2005

Prepared for

the U.S. Army Corps of Engineers, Portland District under Contract 48248

Pacific Northwest National Laboratory

Richland, Washington, 99352 


\begin{abstract}
Dungeness crab studies conducted in 2002 for the Portland District of the U.S. Army Corps of Engineers (Corps) constituted a major step forward in quantifying crab entrainment through statistical projections of adult equivalent loss (AEL) and loss to the fishery (LF) from proposed construction and maintenance dredging in the Columbia River navigation channel (Pearson et al. 2002, 2003). These studies also examined the influence of bottom salinity on crab abundance and entrainment rates. Additional sampling was conducted in 2004 to improve loss projections, further develop the crab salinity model, and apply the model to assess correlations of entrainment rates and projected losses with seasonal salinity changes.
\end{abstract}

Measurements of crab-entrainment rates were made aboard the Corps Dredge, Essayons, during August and September 2004 at Flavel Bar, Desdemona Shoals, and the mouth of the Columbia River (MCR). In both 2002 and 2004, rates decreased from the MCR to upriver locations. An appreciable increase, however, was observed in entrainment of age $0+$ crab, populations of which are known to vary among years and episodically within a year. In 2004, entrainment rates at Flavel Bar were similar to those at Upper Sands, which also has similar salinity regimes. Desdemona Shoals, on the other hand, had bottom salinities intermediate between those of the MCR and the upriver locations and also had the most variable entrainment rates. The MCR, dominated by oceanic water with bottom salinities above 28 psu for $98 \%$ of the summer observations, had consistent entrainment rates ( 0.05 to $0.10 \mathrm{crab} / \mathrm{cubic}$ yard).

A statistical procedure for ratio estimation was used to hindcast the 2002 entrainment rates for Flavel Bar from the 2002 and 2004 data, and a modified Dredge Impact Model (DIM) was used to project crab AEL and LF for the dredged volumes proposed for the Channel Improvement Project. The results improved the previous estimates of loss in two ways: first, the estimates were based on site-specific data, and second, the additional 2004 data reduced the variance and narrowed confidence limits. No crab population estimates are available against which to judge the AEL at ages $2+$ and $3+$, although the commercial crab landings from the regions adjacent to the Columbia River enable a comparison based on the LF values.

Regression analysis with the 2002 and 2004 data was used to develop the salinity model for crab occurring in the MCR and navigation channel. The model showed that the natural logarithms of entrainment rates for ages $2+$ and $3+$ crab are significantly related to salinity. As the salinity decreases from oceanic values, the entrainment rates for this age group decrease exponentially. In areas where salinity observations are lower than 16 psu at least $50 \%$ of the time (e.g., near the Astoria Bridge in summer), the model predicts that entrainment rates will be a fraction (less than 6\%) of those where salinity remains below 16 psu only $2 \%$ of the time (e.g., the MCR in summer). According to results, the entrainment of younger crab are governed by factors in addition to or other than salinity.

The model was then used to predict entrainment rates by month from bottom salinity data at two Columbia River Estuary (CORIE) environmental sensor network stations, which act as surrogates for Desdemona Shoals and Flavel Bar. These predicted rates were used with the modified DIM to forecast AEL and LF by month, assuming a dredged volume (60,000 cy) equivalent to one day's dredging by the Corps Dredge, Essayons. This approach enabled comparison of seasonal changes in entrainment rates and losses as a function of salinity. At both stations, there was a pattern to the salinity regimes associated with river flow and time of year (lower salinities in winter/spring). The model predicts that in December through June, the daily entrainment rates for ages $2+$ and $3+$ crab would be about half of those from July through November. Predicted crab losses (AEL and LF) similarly averaged less in the winter/spring than in the summer/fall. This application of the crab salinity model indicates that adjusting the timing of dredging has potential to reduce crab losses. 


\section{EXECUTIVE SUMMARY}

Proposed dredging for the Columbia River Channel Improvement Project has raised concerns about impacts on Dungeness crab in the Columbia River Estuary. During 2002, the Marine Sciences Laboratory of the U.S. Department of Energy's Pacific Northwest National Laboratory performed crab studies for the Portland District of the U.S. Army Corps of Engineers (Corps) at the mouth of the Columbia River (MCR) and in the Lower Columbia River at Desdemona Shoals, Upper Sands, and Miller Sands (Pearson et al. 2002, 2003). These studies constituted a major step forward in quantifying crab entrainment and enabling statistically bounded projections of adult equivalent loss (AEL) of Dungeness crab resulting from proposed construction and maintenance dredging. For areas not sampled in 2002 (Flavel Bar), loss projections were developed assuming entrainment rates equivalent to those in adjacent upriver and downriver sampling areas. These projections could have overestimated or underestimated the losses at Flavel Bar, and led Pearson et al. $(2002,2003)$ to recommend additional sampling at Flavel Bar. This document presents the results of additional sampling at Flavel Bar and other locations in 2004, and projections of losses based on the 2002 and 2004 data.

Pearson et al. $(2002,2003)$ also found evidence that bottom salinity influences crab abundance and entrainment rates, especially for older age classes of crab at lower salinities. Regression analysis of the $2002 \mathrm{crab}$ entrainment and salinity data from both the river and the MCR (Pearson et al. 2002, 2003) revealed a significant regression between the natural logarithm of the entrainment rate and the percentage of bottom salinity observations below 16 practical salinity units (psu) for $2+$ years and older crab. Pearson et al. (2002) recommended further development of the crab salinity model. This document presents the elaboration of the crab salinity model using the 2002 and 2004 data and the application of the crab salinity model to assess how entrainment rates and projected losses vary seasonally with seasonal shifts in salinity regimes.

Procedures for the field work accomplished in 2004 and the application of the 2002 and 2004 data to estimate AEL and loss to the male fishery (LF) for the proposed Channel Improvement Project appear in two previous reports (Pearson et al. 2002, 2003). A statistical procedure for ratio estimation was used to hindcast the 2002 entrainment rates for Flavel Bar from the 2002 and 2004 data. A modified Dredge Impact Model (DIM) elaborated by Pearson et al. (2002, 2003) from Armstrong et al. (1987) and Wainwright et al. (1992) was used to project crab entrainment, AEL, and LF for the dredged volumes proposed for the Channel Improvement Project. Regression analysis with the 2002 and 2004 data was used to develop the crab salinity model. The model was then used to predict entrainment rates by month from bottom salinity data taken over 3 years from two stations in the Environmental Observation and Forecasting System (EOFS) for the COlumbia RIver Estuary (CORIE), an environmental sensor network through the Oregon Graduate Institute. The predicted entrainment rates then became input to the modified DIM to forecast AEL and LF by month, assuming a dredged volume (60,000 cy) equivalent to one day's dredging by the Corps Dredge Essayons. This approach enabled comparison on a constant basis of seasonal changes in entrainment rates and losses as a function of salinity.

Direct measurements of crab-entrainment rates were made aboard the Corps Dredge, Essayons, during August and September 2004. Sampling was conducted at Flavel Bar, Desdemona Shoals, and the MCR while the dredge was conducting maintenance dredging of the navigation channel. A total of 270 basket samples was taken from 91 loads, distributed by location as follows: Flavel Bar, 30 loads; Desdemona Shoals, 18 loads; MCR, 43 loads.

The 2004 sampling fulfilled its first objective by providing direct measurements of entrainment rates at Flavel Bar, which had not been sampled in 2002. The 2004 results indicated that entrainment rates at Flavel Bar were more similar to those at Upper Sands than to those at Desdemona Shoals. The salinity 
regimes at Flavel Bar were fresher than those at Desdemona Shoals and were more similar to the other upriver locations than to Desdemona Shoals.

Entrainment rates varied by dredging location, age class, and year. The entrainment rates from both 2002 and 2004 clearly decreased substantially moving from the MCR and Desdemona Shoals to the other upriver locations. In 2002, the entrainment rates for all age classes were $0.0603 \mathrm{crab} / \mathrm{cy}$ in the MCR, $0.2240 \mathrm{crab} / \mathrm{cy}$ at Desdemona Shoals in June, $0.1190 \mathrm{crab} / \mathrm{cy}$ at Desdemona Shoals in September, 0.0210 crab/cy at Upper Sands, and zero at Miller Sands. In 2004, the entrainment rates for all age classes were $0.0937 \mathrm{crab} / \mathrm{cy}$ in the MCR, $0.0239 \mathrm{crab} / \mathrm{cy}$ at Desdemona Shoals, and $0.0112 \mathrm{crab} / \mathrm{cy}$ at Flavel Bar. For the MCR, the majority of the difference between 2002 and 2004 was derived from an increase in 2004 of age $0+$ crab, which are known to vary substantially among years and episodically within a year. For Desdemona Shoals, the June 2002 entrainment rate for age $1+$ crab $(0.1930 \mathrm{crab} / \mathrm{cy})$ was the highest in the entire data set; whereas the August 2004 entrainment rate for age 1+ crab (zero crab/cy) was tied for the lowest in the data set.

The 2002 and 2004 field data suggest the following:

- The upriver locations (Flavel Bar, Upper Sands, Tongue Point, and Miller Sands) were more dominated by fresh than salt water. The locations from Flavel Bar and upriver had entrainment rates for all age classes that were consistently low (below $0.02 \mathrm{crab} / \mathrm{cy}$ ), and became zero when freshwater occurred at bottom depths most of the time.

- The MCR was dominated by oceanic water with bottom salinities above 28 psu for $98 \%$ of the observations during the summer sampling period. The MCR had entrainment rates that were consistently between 0.05 and $0.10 \mathrm{crab} / \mathrm{cy}$ and reaching $0.18 \mathrm{crab} / \mathrm{cy}$ for one sampling period.

- Desdemona Shoals had bottom salinities intermediate between those of the MCR and the upriver locations. Desdemona Shoals had the most variable entrainment rates, ranging from 0.02 to $0.22 \mathrm{crab} / \mathrm{cy}$.

The dynamics behind the variable entrainment rates at Desdemona Shoals are not fully understood but may involve age $1+$ crab responding to factors other than salinity. Possibilities include predation by older crab or seasonal movements of age $1+$ crab. The route by which age $1+$ crab enter the estuary in the spring is not known.

The results from 2004 sampling enabled the forecasting of AEL and LF at Flavel Bar based on data specific to that location rather than from adjacent locations, thereby avoiding the over- or underestimates discussed in Pearson et al. (2002, 2003). For example, in Pearson at al. (2002), AEL values for age $2+\mathrm{crab}$ as a consequence of construction dredging to $40 \mathrm{ft}$ at Flavel Bar were estimated to be 11,008 crab using June 2002 Desdemona rates, 27,317 crab using September 2002 Desdemona rates, and $270 \mathrm{crab}$ using Upper Sands rates. Our use here of the 2002 rates for Flavel Bar hindcast by ratio estimation from the 2004 data provides an estimated AEL value of 3,682 for the age 2+ crab.

The additional sampling in 2004 improved the estimates of loss from entrainment associated with the Columbia River Channel Improvement Project in two ways. First, the estimates for Flavel Bar are now based on site-specific data rather than extrapolated from data from adjacent areas. Second, the additional 2004 data led to reduced variance and narrower confidence limits. For the combined construction dredging (to $40 \mathrm{ft}$ and from $40 \mathrm{ft}$ to $43 \mathrm{ft}$ ), Pearson et al. (2002) forecasted the $95 \%$ confidence limits for the worst case estimates for AEL at age 2+ to be 38,811 crab to 281,528 crabs and for LF to be 7,252 crab to 44,342 crab. With the site-specific entrainment rates at Flavel Bar and the same dredged volumes used by Pearson et al. (2002) for the combined construction increments, we now forecast the $95 \%$ confidence limits to be 64,886 to 201,600 crab for AEL at age $2+$ and 10,218 to 31,753 crab for the LF. 
No population estimates are available against which to judge the AEL at ages $2+$ and $3+$. However, the commercial crab landings from the regions adjacent to the Columbia River enable a comparison based on the LF values. The 10-year average for the annual crab landings from the Washington and Oregon regions around the Columbia River is 5.3 million crab. The upper 95\% confidence limit for the LF forecast from the 2002 and 2004 data is less than $0.6 \%$ of the 10-year average annual commercial crab landings from the regions in and around the Columbia River.

The 2004 data enabled further elaboration of the crab salinity model for crab occurring in the MCR and South Channel of the estuary. The main feature of the model remained the same as in Pearson et al. (2002), i.e., the natural logarithms of the entrainment rates for ages $2+$ and $3+$ crab (but not for age $0+$ and $1+\mathrm{crab}$ ) were significantly related to the proportion of bottom salinity observations less than 16 psu. The finding that the regression equations for age $2+$ crab alone and age $3+$ crab alone did not differ significantly suggests that older age classes are responding to salinity in the same way. The results indicate that the entrainment of the age $0+$ and $1+$ crab are governed by factors in addition to or other than salinity. The regression results also indicate that factors other than bottom salinity influence entrainment of older crab when salinity approaches oceanic values (above $32 \mathrm{psu}$ ). As the salinity decreases from oceanic values, the entrainment rates for ages $2+$ and $3+$ crab decrease exponentially. The model predicts that in areas where salinity observations are lower than 16 psu at least $50 \%$ of the time (e.g., the summer salinity values near the Astoria Bridge), entrainment rates will be a fraction (less than 6\%) of those where salinity remains below 16 psu only $2 \%$ of the time (e.g., the summer values in the MCR).

The crab salinity model was applied to forecast monthly entrainment rates from a 3-year record of bottom salinity measurements at two CORIE stations: AM169 and RED26. The two stations, RED26 and AM169, act as surrogates, respectively, for Desdemona Shoals and for Flavel Bar and the upriver locations.

There is a seasonal pattern to the salinity regimes and thus to the entrainment rates for ages $2+$ and $3+$ crab. Bottom salinity at AM169 is almost completely dominated by freshwater from December through June and dominated by freshwater even in summer and fall (July through November). Predicted age 2+ and 3+ crab-entrainment rates for the AM169 data are very low in winter and spring (less than 0.0005 $\mathrm{crab} / \mathrm{cy}$ ) and low in the summer and fall (about $0.001 \mathrm{crab} / \mathrm{cy}$ ). RED26 near Desdemona Shoals has salinity regimes intermediate between the MCR and other river locations but with the same seasonal patterns (more saline from July through November). Predicted age $2+$ and $3+$ crab-entrainment rates from the RED26 data are less than $0.0015 \mathrm{crab} / \mathrm{cy}$ in the winter and spring, and from 0.0025 to 0.0035 $\mathrm{crab} / \mathrm{cy}$ in the summer and fall. The highest predicted rate from the RED26 data is about $0.0035 \mathrm{crab} / \mathrm{cy}$ in July. For both RED26 and AM169, the predicted winter/spring entrainment rates for ages 2+ and 3+ crab are about half of the predicted summer/fall entrainment rates.

The losses (AEL and LF) predicted for 60,000 cy averaged less in the winter/spring than in the summer/fall. For the AM169 data, predicted values for AEL at age 2+ were $256 \mathrm{crab}$ per month for December through June, and $373 \mathrm{crab} /$ month from July through November. For the RED26 data, predicted values for AEL at age 2+ were $362 \mathrm{crab}$ per month for December through June, and 636 $\mathrm{crab} /$ month from July through November. The difference in predicted values for AEL at age $2+$ between summer/fall and winter/spring was greater for RED26 (43\% decrease) than for AM169 (31\% decrease). This application of the crab salinity model indicates that adjusting the timing of dredging has potential to reduce crab losses. 


\section{ACKNOWLEDGEMENTS}

This study would not have been possible without the assistance of Captain Nyberg, Captain Holcroft, and each crew member aboard the Corps Dredge Essayons. Their accommodating attitude provided a safe, enjoyable working atmosphere that enabled us to meet all of our project goals. We would also like to thank the Pacific Northwest National Laboratory field crew: Nathan Evans, Nancy Kohn, John Southard, Julie Pecore, and Jeff Ward, as well as Corps intern Bryan Mason, who often worked under difficult field conditions. The quality of this data is a tribute to their hard work and dedication. This work was supported by the Portland District Corps. Mr. Kim Larson was the Corps Technical Representative. Ms. Doris McKillip was the Corps Project Manager for the Mouth of the Columbia River Dredging Project. Shyam Nair, E2 Consulting, analyzed and summarized the datasets from the Environmental Observation and Forecasting System (EOFS) for the COlumbia RIver Estuary (CORIE), provided by the Oregon Graduate Institute. 


\section{ACRONYMS / ABBREVIATIONS}

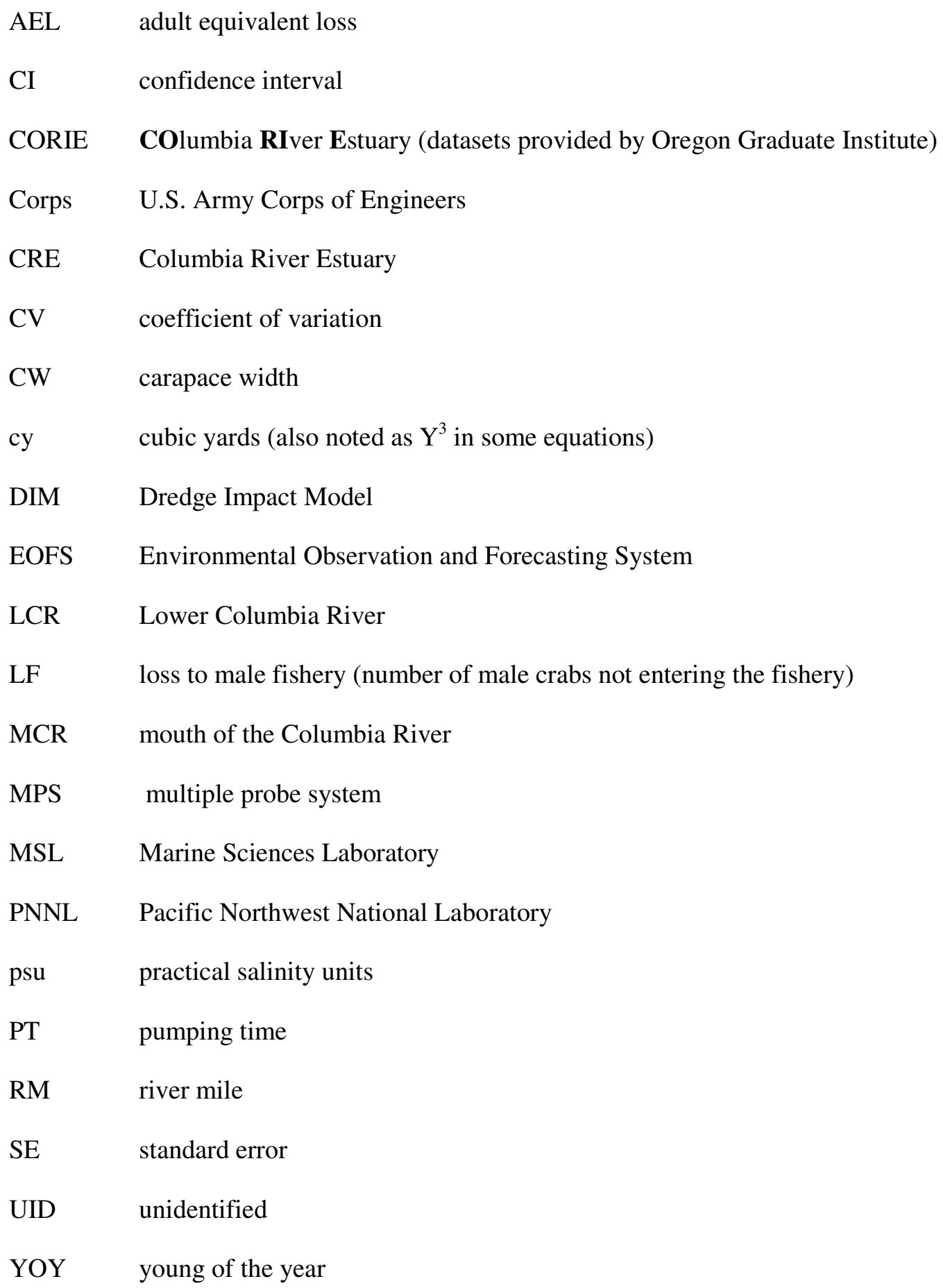




\section{CONTENTS}

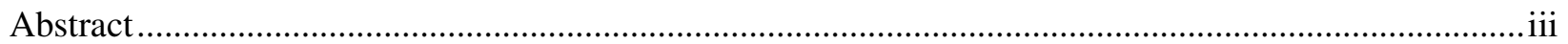

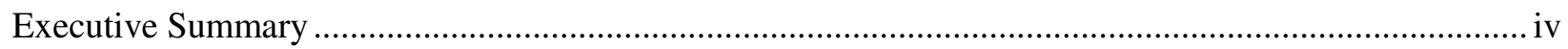

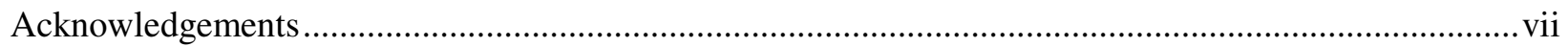

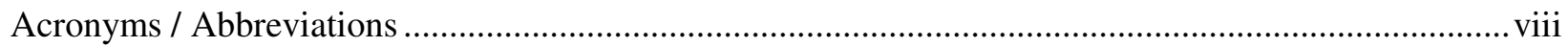

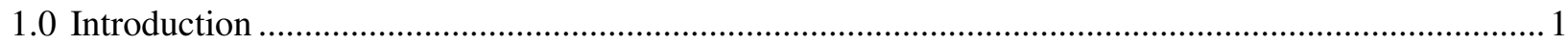

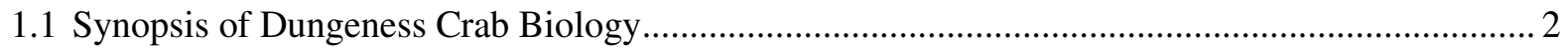

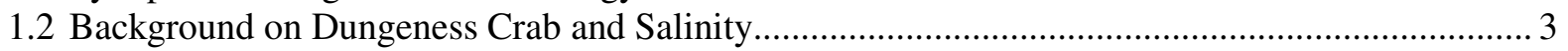

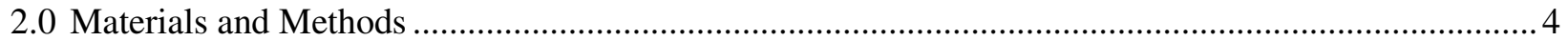

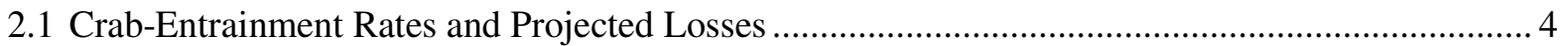

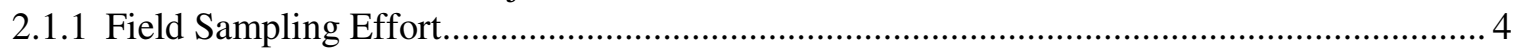

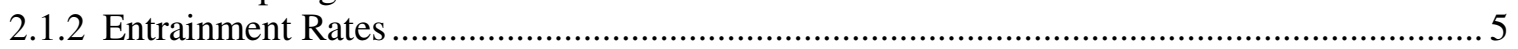

2.1.3 Flavel Bar Interannual-Entrainment-Rate Ratio Estimate.................................................... 5

2.1.4 Dredge Impact Model - Estimating AEL and LF from Channel Deepening......................... 7

2.1.5 Statistical Analyses and Calculation of Variance and Confidence Limits ............................ 8

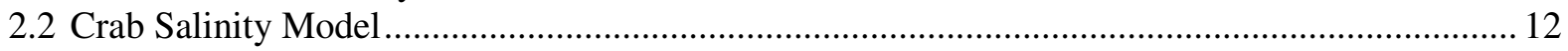

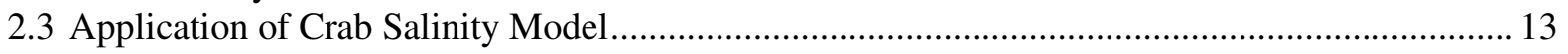

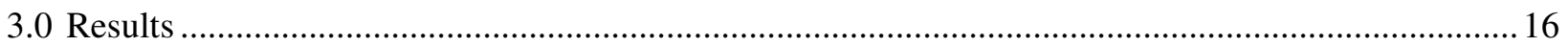

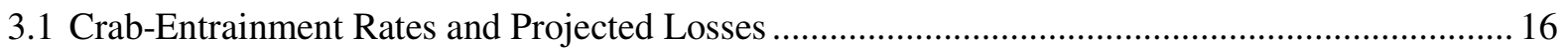

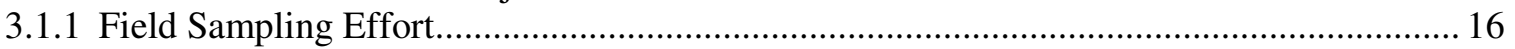

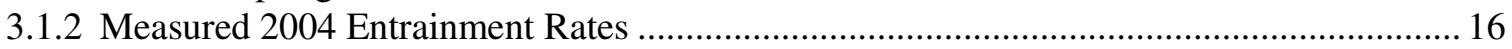

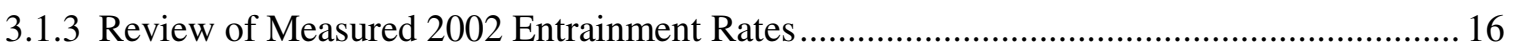

3.1.4 Comparison Between 2002 and 2004 Entrainment Rates ................................................ 16

3.1.5 Interannual-Entrainment-Rate Ratio Estimate ................................................................ 17

3.1.6 Dredge Impact Model - Estimating Adult Equivalent Loss and Loss to Male

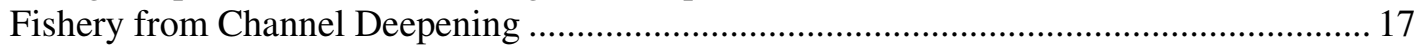

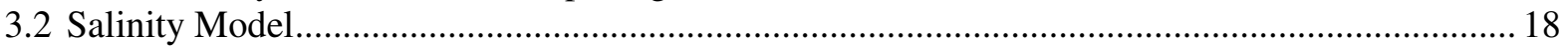

3.3 Application of Crab Salinity Model............................................................................. 18

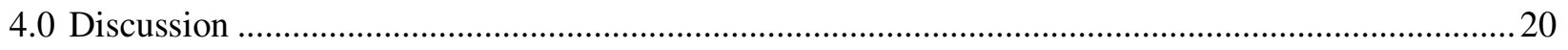

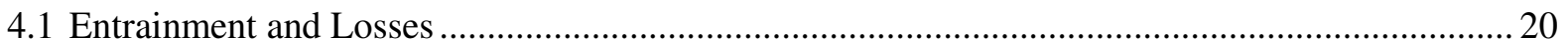

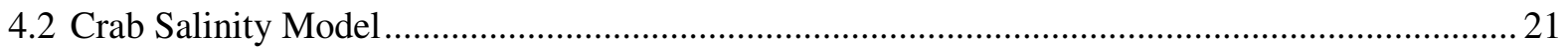

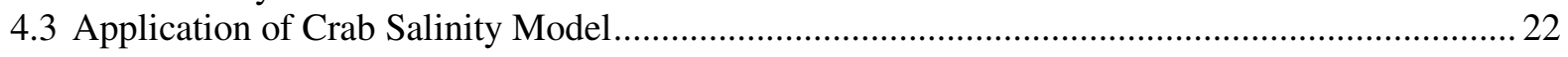

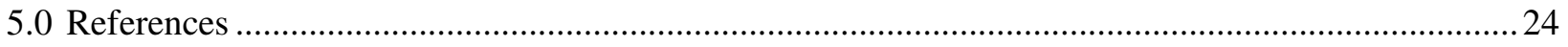

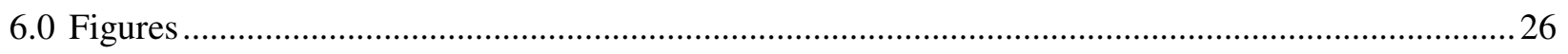

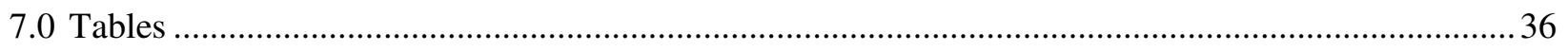

Appendixes 


\section{FIGURES}

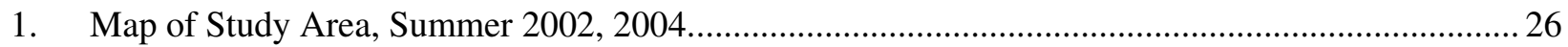

2. The Structure of a Modified Model for Estimating Dredging-Entrainment Impacts on Dungeness Crab (Modified from Armstrong et al. 1987)

3. Mean $( \pm \mathrm{SE})$ Crab-entrainment rates (crab/cy) by location during comparable periods in 2002 to 2004 for all age classes .28

4. Mean ( \pm SE) entrainment rates (see Table 6) of Dungeness Crab in 2002 and 2004 by age class, at Desdemona Shoals and the Mouth of the Columbia River (2004 Flavel Bar values shown for comparison).

5. Mean $( \pm$ SE) entrainment rates of Dungeness Crab by age class in 2002 and 2004 at the Mouth of the Columbia River, Desdemona Shoals, and Flavel Bar (2002 Flavel Bar values based on weighted estimation).

6. The relationship of entrainment rate ( $\mathrm{R}$ as crab/cy) to bottom salinity (as proportion of salinity observations less than $16 \mathrm{psu}$ ) using 2002 and 2004 data.

7. Predicted monthly entrainment rates $(\mathrm{R})$ of age $2+$ or age $3+$ crab using bottom salinity data from CORIE Station AM169.

8. Predicted monthly entrainment rates $(\mathrm{R})$ of age $2+$ or age $3+$ crab using bottom salinity data from CORIE Station RED26.

9. Predicted total daily entrainment (E) of crab (all age classes) by month at CORIE Stations AM169 and RED26 based on salinity model regressions and assuming a dredging volume of $60,000 \mathrm{cy}$.

10. Projected daily (assuming 60,000 cy dredged/day) crab adult equivalent loss at ages $2+$ and $3+$ and loss to fishery, by month, based on bottom salinity data from CORIE Station AM169 35

11. Projected daily (assuming 60,000 cy dredged/day) crab adult equivalent loss at ages $2+$ and $3+$ and loss to fishery based on bottom salinity data by month from CORIE Station RED26. 35

\section{TABLES}

1. Projected precision (CV) for Flavel Bar entrainment rates in 2002, based on sampling effort

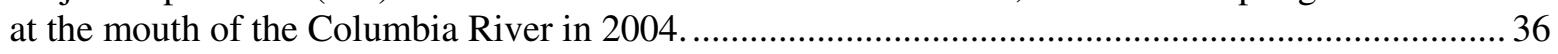

2. Crab Entrainment Sampling Effort by Location during 2002 and 2004 ........................................ 37

3. Summary of Bottom Salinity and Total Number of Dungeness Crab (by Age Class), Crangon Shrimp, and Razor Clams Collected in Samples at Each Field Location in 2004.............. 38

4. 2004 Entrainment Rates (R) (crab/cy) by Crab Age Class............................................................... 38

5. 2002 Entrainment Rates (R) (crab/cy) by Crab Age Class (From Pearson et al. 2002; 2003)........... 39

6. Entrainment-Rate Data Used for Estimation of Flavel Bar 2002 Entrainment Rates ........................ 39

7. Site-Specific Ratio Estimator Table of 2002 Flavel Bar Entrainment Rates. ................................... 39

8. Projected Dredge Volumes for Future Construction Dredging (to $40 \mathrm{ft}$ and from $40 \mathrm{ft}$ to $43 \mathrm{ft}$ ) Associated with the Columbia River Channel Improvement Project. 
9. Summary of Projected Dredged Materials Volumes (cy) by Location for Future

Construction Scenarios in River.

10. Crab Adult Equivalent Loss (Ages 2+ and 3+) and Loss to Male Fishery Projected for Construction Dredging to $40 \mathrm{ft}$.....

11. Crab Adult Equivalent Loss (Ages 2+ and 3+) and Loss to Male Fishery Projected for Construction Dredging from $40 \mathrm{ft}$ to $43 \mathrm{ft}$.

12. Summary of Adult Equivalent Loss at Ages 2+ and 3+, and Losses to Fishery for Construction Dredging with 95\% Confidence Limits.

13. Results of Regressions Involving Entrainment Rate (R, as Crabs/cy) and Bottom Salinity (Proportion of Observations Below or Above a Given Salinity Value (psu).

14. Monthly Availability of Bottom Salinity Data from CORIE Station AM169 during 20012003 (Shading Indicates Data Available)

15. Monthly Availability of Bottom Salinity Data from CORIE Station RED26 during 20012003 (Shading Indicates Data Available).

16. Monthly Predictions of Crab-Entrainment Rates (crab/cy) by Age Class at AM169.

17. Monthly Predictions of Crab-Entrainment Rates (crab/cy) by Age Class at RED26.

18. Projected Daily Entrainment, AEL 2+, AEL 3+, and LF by Age Class and Month at AM169, Using Dredge Impact Model.

19. Projected Daily Entrainment, AEL 2+, AEL 3+, and LF by Age Class and Month at RED26, Using Dredge Impact Model. 45 


\subsection{INTRODUCTION}

Proposed dredging of the Columbia River has raised concerns about impacts on Dungeness crab in the Columbia River Estuary (CRE). During 2002, the Marine Sciences Laboratory (MSL) of the U.S. Department of Energy Pacific Northwest National Laboratory (PNNL) performed crab studies for the Portland District of the U.S. Army Corps of Engineers (Corps) at the mouth of the Columbia River (MCR) and in the Columbia River at Desdemona Shoals, Upper Sands, and Miller Sands (Pearson et al. 2002, 2003). These studies constituted a major step forward in quantifying crab entrainment, and enabled statistically bounded projections of adult equivalent loss (AEL) of Dungeness crab for proposed dredged volumes during construction and maintenance dredging.

For areas not sampled in 2002 (e.g., Flavel Bar), loss (AEL) projections were developed that assumed entrainment rates equivalent to those in adjacent upriver and downriver sampling areas. These projections could have overestimated or underestimated the loss at Flavel Bar, and led Pearson et al. $(2002,2003)$ to recommend additional sampling at Flavel Bar. This document presents results based on this additional sampling at Flavel Bar and other locations in 2004.

Pearson et al. (2002, 2003) also found evidence that bottom salinity influences crab abundance and entrainment rates, especially for older age classes of crab at lower salinities. Modeling the previous data of Stevens and Armstrong (1984) revealed a logarithmic relationship between crab density and mean bottom salinity for age 1+ and older crab. Regression analysis of the 2002 crab entrainment and salinity data from both the river and the MCR (Pearson et al. 2002, 2003) revealed a significant regression between the natural logarithm of the entrainment rate and the percentage of salinity observations below $16 \mathrm{psu}$ for age $2+$ and older crab. The variation in entrainment rates of age $1+$ crab, especially at Desdemona Shoals, suggested a more complex dynamic concerning the distribution of age $1+$ crab. Pearson et al. (2002) recommended further development of the crab salinity model. This document develops the crab salinity model based on 2002 and 2004 entrainment data, and presents results of applying the model to assess how predicted entrainment rates and projected losses change with seasonal shifts in bottom salinity.

The overall goal of this study was to provide analysis for assessing potential impacts on Dungeness crab by dredging entrainment at upriver locations in the CRE based on data collected in 2002 and 2004.

Specific objectives necessary to meeting this overall goal were to

- Complete additional field entrainment studies of Dungeness crab in 2004 at Flavel Bar, as well as at two other locations sampled previously: Desdemona Shoals and MCR. This sampling effort is designed to fill data gaps and reduce uncertainties about potential crab entrainment at Flavel Bar, while separating inter-year effects from location effects.

- Analyze the resulting data under statistically appropriate and effective protocols

- Use the entrainment rates and their associated error in the modified dredge impact model (DIM) to gain population-level perspective on the potential impacts of entrainment at these areas during 2002

- Determine and apply relationships between crab-entrainment rates and bottom water salinity to identify adaptive management options for dredging in the estuary.

This document describes the field work accomplished in 2004 and the results of applying the 2002 and 2004 data to estimate AEL and loss to the male fishery (LF) for the proposed Columbia River deepening project. Two previous reports (Pearson et al. 2002, 2003) provide more detail on the work accomplished in 2002 and the methods used in both 2002 and 2004. Past studies have shown that Dungeness crab is entrained during dredging (Armstrong et al. 1987; Wainwright et al. 1992; Larson 1993). The age-class 
composition of entrained crab can vary by estuarine location and season. Mortality following entrainment and natural survival also varies by age class. A modified DIM from Armstrong et al. (1987) and Wainwright et al. (1992) used the entrainment rates and the volume of materials to be dredged during the Channel Improvement Project to project crab entrainment, AEL, and LF. This document also describes the development of the crab salinity model and its application to assess how predicted entrainment rates and losses vary with seasonal changes in bottom salinity. A short background on the biology of Dungeness crab and the influence of salinity on crab distribution and entrainment rates follows immediately below.

\subsection{Synopsis of Dungeness Crab Biology}

The distribution and abundance of Dungeness crab is governed by movements related to life history events (e.g., mating, rearing) and by abiotic and biotic environmental factors (temperature, salinity, tidal and lunar cycles, predation). How these factors lead to the vulnerability of crab to dredging activity was discussed by Pearson et al. (2002) and is summarized briefly here.

Over their life cycle, Dungeness crab occur in and move between the nearshore oceanic environment and the estuary (Tasto 1983; Armstrong et al. 1987; Rooper et al. 2002). Fertilization, egg-bearing, hatching, and much, if not most, of the larval development occur in the ocean. Foraging and rearing occur in the estuary as well as in the ocean. In the spring, the megalopae, the last larval stage, settle to the bottom in both the ocean and the estuary to become the first crab instar stage (Young of the Year or YOY). Large numbers of megalopae and YOY crab can enter the estuary in the spring and early summer. In the estuary, YOY (age 0+) crab occur in intertidal and shallow subtidal areas on substrates with shell hash, eelgrass, or other shelter (Armstrong et al. 1987). After growing to 20 -mm carapace width (CW), age $0+$ crab move from intertidal to subtidal areas. Age $0+$ crab in the estuary grow faster than those in the ocean. Juvenile crab (age 1+) found in the estuary derive either from age $0+$ crab that over-wintered in the estuary or from age 1+ crab entering the estuary in the spring. Age 1+ crab occur in subtidal areas and forage over intertidal areas during high tide. Movements of age 1+ crab related to life history events occur in the fall when age $1+$ crab leave the estuary for the ocean and in the spring when age $1+$ crab leave the ocean to enter the estuary.

In the Columbia River, Dungeness crab are found from the MCR to about River Mile (RM) 17 (McCabe et al. 1986, 1989). In spring and summer, age 0+ crab can be found in the MCR and the estuary with annual average densities varying over two orders of magnitude from year to year (Larson 1993). In the fall of 2003, Williams et al. (2004) observed an abrupt increase of the density of age 1+ crab in shallow subtidal areas south of the north jetty in the MCR.

It is clear that Dungeness crab use not only estuarine navigation channels but also other estuarine habitat areas. A recent survey of four West Coast estuaries by Rooper et al. (2002) indicates that Dungeness crab show consistent use of some estuarine habitat types. Side-channel habitat near the estuary mouth has the highest crab densities; the lower estuarine main channel and upper estuary have significantly lower densities. The characteristics of the preferred lower side-channel habitat include shell, macroalgae, shallow depths, high food abundance, temperatures $<18 \mathrm{EC}$, and salinities above 25 practical salinity units (psu).

Use of the estuary by Dungeness crab is important. The coastal estuaries are estimated to be the basis for $20 \%$ to $40 \%$ of West Coast Dungeness crab fishery production (Armstrong, personal communication). The estuaries appear to provide relatively steady contributions to annual crab production, whereas nearshore ocean environments provide crab production that is quite variable from year to year (Armstrong, personal communication). 


\subsection{Background on Dungeness Crab and Salinity}

Salinity has long been suspected to be a factor in the distribution and abundance of Dungeness crab in West Coast estuaries (Tasto 1983; Stevens and Armstrong 1984; McCabe et al. 1986). Pearson et al. (2002) summarized the information on the interaction of crab distribution and bottom salinity and used the information gained from the 2002 field sampling to develop a model that relates entrainment rates and bottom salinity. The scientific literature, scenario analyses, and the summer 2002 site-specific data on entrainment and salinity all indicate that bottom salinity influences crab entrainment, especially at estuarine but not oceanic values.

The modeling by Pearson et al. (2002, 2003) of the previous data of Stevens and Armstrong (1984) on Dungeness crab and bottom salinity revealed that mean station density for age $1+$ and older crab is logarithmically related to mean bottom salinity. The relationship between salinity and age $0+\mathrm{crab}$ density appears to be more complex. The significant regression derived from this analysis enabled forecasting of crab density from salinity data. For example, predicted crab density at a bottom salinity of 16 psu is less than $1 \%$ of that at 32 psu.

Pearson et al. $(2002,2003)$ used the data specific to the MCR and Lower Columbia River (LCR) to elaborate a model of the influence of salinity on crab-entrainment rates along the South Channel. In summer 2002, entrainment rates fell as the bottom waters became fresher. At Miller Sands, where bottom salinities were less than 16 psu for $100 \%$ of the salinity measurements, no crab or crab parts were entrained in any of the 140 basket samples. In the MCR, where bottom salinities were above 28 psu for $98 \%$ of salinity measurements, crab were consistently entrained over the course of the summer sampling. For the combined age classes of age 1+ and older, regression analysis showed that the natural logarithms of the entrainment rate for each dredged area were significantly related to the percentage of salinity observations less than 16 psu but not to the percentage of salinity observations above 32 psu. For age 1+ crab alone, the natural logarithms of the entrainment rates were not significantly related to either measure of salinity. For age 2+ and older, regression analysis revealed that the natural logarithms of the entrainment rates were significantly related to both the percentage of observations of salinity above 32 psu and the percentage below 16 psu. The highest percentage of the variation in regressions was seen in the percentage of observations of salinity less than $16 \mathrm{psu}$.

This last result is supported by physiological studies that indicate that Dungeness crab are weak osmoregulators and become stressed and inactive at 16 psu (Brown and Terwillger 1992, 1999; McGaw and McMahon 1996; McGaw et al. 1999). Also, McCabe et al. (1986) found no crab at stations with average bottom salinities of 3.5 psu and 8 psu (above RM18) and found crab only "infrequently" at stations with average bottom salinities of 15.9 psu (about RM14) and 20.2 psu (about RM12). The relationship of the age 1+ crab-entrainment rates to salinity appears to be more complex than that for the age $2+$ and older crab, for which the regressions between the logarithm of crab-entrainment rate and the percentage of salinity observations below 16 psu were significant and explained a high degree (91\%) of the variation. Pearson et al. (2002) hypothesized that at bottom salinities above $30 \mathrm{psu}$, crab density is governed by factors other than salinity, and that as bottom salinity falls below $30 \mathrm{psu}$, crab density falls logarithmically.

Pearson et al. (2002) indicated that the model for the influence of salinity on crab distribution and entrainment needs further development. Here we report on the elaboration of the crab salinity model using data from both 2002 and 2004. Also, we report on the application of the crab salinity model to forecast entrainment rates and AEL under seasonal variation of salinity in the LCR. 


\subsection{MATERIALS AND METHODS}

Entrainment rate data collected in 2002 (Pearson et al. 2002, 2003) were used to estimate other entrainment rates (Section 2.1.3), project potential crab losses associated with the Channel Improvement Project (2.1.4), and develop the crab salinity model (Section 2.2). This 2004 study initially involved field collection of additional crab-entrainment rate data that were used to supplement this 2002 information.

\subsection{Crab-Entrainment Rates and Projected Losses}

\subsubsection{Field Sampling Effort}

Researchers conducted crab-entrainment studies aboard the Corps dredge, Essayons, in 2004, using the methods described in previous reports (Pearson et al. 2002, 2004). A brief overview of these methods, with a description of relevant modifications, is provided below.

In previous years, the data used for estimating crab-entrainment rates were derived from a two-stage sampling scheme that involved random sampling of 1) approximately half of the loads collected by the dredge, and 2) dredged material (at least three basket samples) within a selected load. Logistical constraints imposed by the 2004 dredge schedule (maximum of 2 to 3 days at a particular upriver site), necessitated that the sampling design be modified such that all loads were sampled while researchers were aboard the dredge. Basket samples were randomly distributed through the period of load collection (approximately 1 hour), as in previous efforts. Minimum sample size (loads) estimates for the MCR are outlined in Section 2.1.3.

Four sets of data sheets were used to record field data: load-by-load records, sample records, within-load records, and a daily log. Total load volumes (cubic yards) and distances (feet) for all loads during the duration of the survey were obtained from the Essayons dredge logbook and recorded on the load-by-load sheets. Data on individual basket samples taken within a load, including numbers, size, and sex of Dungeness crab entrained, were recorded on sample record sheets. Basket sample volume and numbers of crab, fish, and molluscs in each sample were summarized on within-load record sheets. Pertinent weather conditions, personnel involved, dredge operations, and deviations from normal operating procedures (e.g., repairs, gear modification), were noted in the daily log.

On-deck sampling followed methods previously used to operate the crab basket sampler and gate valve (Pearson et al. 2002, 2003). Sampling time intervals were guided by the volume of dredged material that could be reliably sorted within the course of a load. At the MCR, this time period was generally 45 seconds, whereas at upriver sites it decreased to approximately 30 seconds from valve opening to final closure. Sample volume was calculated by multiplying effective sampling time $(\mathrm{t})$ by mean load rate (cy/t) of the discharge pipe feeding the basket sampler. As in Larson (1993), mean load rates of the discharge pipe were calculated on a load-by-load basis by dividing total pumping time by total load volume in cubic yards. All calculations of sediment load and crab-entrainment rate used a factor of 0.25 to correct for the proportion of total flow (load rate) diverted into the basket sampler. Procedures for calculating sample volumes took into account the depth of fluid in the pipe (assuming the pipe was half full) and the timing of opening and closing the hydraulic gate valves. Additional details on the calculation of effective sampling time are provided in Pearson et al. 2002.

After completing collection of each basket sample, the temperature (degrees Celsius) and salinity (practical salinity units) of pumped seawater was obtained from a catch pan under the basket sampler system using a YSI Model 556 multiple probe system (MPS). Whole and parts of living organisms were sorted from the sample, and individuals from the following taxa were identified and enumerated: crab 
(Cancer magister and other species), shrimp (e.g., Crangon spp.), razor clam, and all fish species. In cases in which an animal other than crab was crushed or pieces were collected, the animal was counted only if the head was present (see details below on quantifying crushed crab). Researchers noted the relative abundance of other species (e.g., olive snail, polychaetes) and recorded the species and total length (length from the tip of the upper jaw to the end of the caudal fin) of fishes.

Calipers were used to measure the $\mathrm{CW}$ of all crab, and the sex of larger crab was determined. If $1 / 2 \mathrm{a}$ crab carapace was present, this portion was measured and used to estimate total CW. In cases in which a crab was crushed or in pieces, only individuals for which more than 1/2 a carapace, or other matched pieces (e.g., telson, legs, chela, thorax) constituting $1 / 3$ of a crab, were quantified. When these criteria were not met (e.g., only 2 legs collected), the presence of crab pieces was qualitatively recorded with a "YES" under the unidentified (UID) crab column on the record sheet. All crab and crab pieces were dumped into the dredge hopper to prevent duplicate counts on subsequent passes.

\subsubsection{Entrainment Rates}

Entrainment rates (as crab entrained per cubic yard of sediment dredged) were calculated by crab age class and sex based on sampling conducted directly on the dredge (previously described in Section 2.1.1). These rates were location-specific and generally corresponded to five areas where dredging of the navigation channel normally occurs: MCR, Desdemona Shoals, Flavel Bar, Miller Sands, and Upper Sands (Figure 1). As previously described, location-specific entrainment rates provided the basis for additional calculations, such as potential crab losses associated with the Channel Improvement Project (Section 2.1.4) and the crab entrainment salinity model (Section 2.2).

\subsubsection{Flavel Bar Interannual-Entrainment-Rate Ratio Estimate}

One prominent goal of the 2004 crab-entrainment study was to estimate crab-entrainment rates at Flavel Bar in 2002 based on 2004 sampling data. A ratio estimator was used to estimate the Flavel Bar abundance in $2002\left(\mathrm{FB}_{02}\right)$, based on observed values at Flavel Bar in $2004\left(\mathrm{FB}_{04}\right)$, at the MCR in 2002 $\left(\mathrm{MCR}_{02}\right)$ and $2004\left(\mathrm{MCR}_{04}\right)$, and similarly for Desdemona Shoals in 2002 and 2004 . Using the MCR data as an example, expressed in terms of entrainment rates, it might be expected that

$$
\frac{\mathrm{FB}_{04}}{\mathrm{MCR}_{04}}=\frac{\mathrm{FB}_{02}}{\mathrm{MCR}_{02}},
$$

assuming multiplicative annual effects. In which case, Equation (1) provides the estimator

$$
\widehat{\mathrm{FB}}_{02}=\left(\frac{\widehat{\mathrm{FB}}_{04}}{\widehat{\mathrm{MCR}}_{04}}\right) \widehat{\mathrm{MCR}}_{02} \text {. }
$$

The variance of $\widehat{\mathrm{FB}}_{02}$ can be expressed as

$$
\operatorname{Var}\left(\widehat{\mathrm{FB}}_{02}\right)=\widehat{\mathrm{FB}}_{02}^{2}\left[\mathrm{CV}\left(\widehat{\mathrm{FB}}_{04}\right)^{2}+\mathrm{CV}\left(\widehat{\mathrm{MCR}}_{04}\right)^{2}+\mathrm{CV}\left(\widehat{\mathrm{MCR}}_{02}\right)^{2}\right] \text {, }
$$

or the coefficient of variation $(\mathrm{CV}$, i.e., precision)

$$
\mathrm{CV}\left(\widehat{\mathrm{FB}}_{02}\right)=\sqrt{\mathrm{CV}\left(\widehat{\mathrm{FB}}_{04}\right)^{2}+\mathrm{CV}\left(\widehat{\mathrm{MCR}}_{04}\right)^{2}+\mathrm{CV}\left(\widehat{\mathrm{MCR}}_{02}\right)^{2}} .
$$

Equation (4) considers what levels of precision are needed for $\mathrm{MCR}_{04}$ and $\mathrm{FB}_{04}$ to attain a prescribed level of precision for $\mathrm{FB}_{02}$.

Sample size calculations were conducted to determine the minimum 2004 sampling effort at the MCR that would allow reliable precision for estimating 2002 Flavel Bar entrainment rates using the ratio estimator, while working within the inherent sample size limitations (predicted to be approximately $\mathrm{n}=17$ ) at Flavel Bar and Desdemona Shoals. A ratio estimator can be used to estimate the Flavel Bar abundance 
in $2002\left(\mathrm{FB}_{02}\right)$, based on observed values at Flavel Bar in $2004\left(\mathrm{FB}_{04}\right)$ and at the $\mathrm{MCR}$ in $2002\left(\mathrm{MCR}_{02}\right)$ and $2004\left(\mathrm{MCR}_{04}\right)$. As a rough approximation from 2002,

$$
\mathrm{CV}\left(\mathrm{MCR}_{02}\right)=0.04275=\sqrt{\frac{\left(1-\frac{n}{N}\right)}{n}} \cdot \frac{s}{\bar{x}} .
$$

Setting prior sample sizes,

$$
\begin{aligned}
0.04275 & =\sqrt{\frac{\left(1-\frac{214}{489}\right)}{214}} \cdot\left(\frac{s}{\bar{x}}\right) \\
\frac{s}{\bar{x}} & =0.8339,
\end{aligned}
$$

the relative load-to-load variability observed in 2002. Using these assumed relationships,

where

$$
\mathrm{CV}\left(\widehat{\mathrm{FB}}_{02}\right) \doteq \sqrt{(0.0619)^{2}+(0.04275)^{2}+\left(\frac{1}{n}-\frac{1}{N}\right)(0.8339)^{2}}
$$

$n=$ number of loads sampled,

$N=$ number of loads performed at the mouth MCR in 2004.

Ignoring the finite population correction,

$$
\mathrm{CV}\left(\widehat{\mathrm{FB}}_{02}\right)=\sqrt{0.005659+\frac{0.6954}{n}}
$$

Various values of $\mathrm{CV}$ for $\mathrm{FB}_{02}$ were projected for alternative values of $n$ (Table 1).

Equation (4) indicates that the precision of the projection of the Flavel Bar entrainment rates in 2002 is a simple function of the precision (i.e., $\left.\mathrm{CV}^{2}\right)$ of the three input parameters. The value of $\mathrm{CV}\left(\mathrm{MCR}_{02}\right)$ is a historical and fixed value with which we must now accept. The $\mathrm{CV}\left(\mathrm{FB}_{04}\right)$ is unknown, but given the expected low density of crab, the CV might be similar or smaller than other upriver sites. Furthermore, vessel time limitations will restrict effort at Flavel Bar to 2 to 3 days (i.e., .17 loads). Hence, the only design option with some flexibility is the number of loads to sample at the MCR. Table 1 indicates precision levels of approximately $n=40$ to 50 loads, with little additional gain with more sampling effort.

Hence, it was recommended that between 40 and 50 loads be sampled at the MCR in 2004. Furthermore, for the MCR estimates in 2004 to be comparable with those in 2002, sampling must also be spatially representative of past efforts. Therefore, loads were subsampled over time to better characterize overall MCR entrainment rates in 2004.

Because entrainment rates at Flavel Bar in $2002\left(\widehat{\mathrm{FB}}_{02}\right)$ were based on data derived from two locations (MCR and Desdemona Shoals), a weighted average was used to account for each estimate's associated variance. The weighted average was calculated as: 


$$
\hat{\hat{\theta}_{W}}=\frac{\sum_{i=1}^{k} W_{i} \hat{\theta}_{i}}{\sum_{i=1}^{k} W_{i}}
$$

where

$$
\begin{aligned}
& W_{i}=\text { weight for the ith estimate }(i=1, \ldots, k) \text { as } \frac{1}{\operatorname{Var}\left(\hat{\theta}_{i}\right)} ; \\
& \hat{\theta}_{i}=\text { ith estimate }(i=1, \ldots, k) .
\end{aligned}
$$

The variance for some weighted average of these ratio estimates is calculated as follows:

$$
\widehat{\operatorname{Var}}\left(\hat{\bar{\theta}}_{W}\right)=\frac{\sum_{i=1}^{k} W_{i}\left(\hat{\theta}_{i}-\hat{\bar{\theta}}_{W}\right)^{2}}{(k-1) \sum_{i=1}^{k} W_{i}} .
$$

The standard error (SE) is then

$$
\widehat{\mathrm{SE}}\left(\hat{\hat{\theta}_{W}}\right)=\sqrt{\widehat{\operatorname{Var}}\left(\hat{\bar{\theta}}_{W}\right)} .
$$

\subsubsection{Dredge Impact Model - Estimating AEL and LF from Channel Deepening}

Armstrong and his colleagues (Armstrong et al. 1987; Wainwright et al. 1990; Wainwright et al. 1992) developed the DIM for use in the Grays Harbor Navigation Improvement Project for the Corps Seattle District. The model evolved over the years, and Wainwright et al. (1992) gives a succinct overview of its present form. In reviewing the model for use in gaining perspective on crab impacts in the Columbia River, Pearson et al. (2002) found the model structure to be generally applicable, but the entrainment function and the available data on crab density were not appropriate for estimating the effects of dredging on the Columbia River crab population and crab fishery. More details of this analysis appear in Pearson et al. $(2002,2003)$.

To calculate crab entrainment, AEL, and LF for projected dredged volumes associated with the Channel Improvement Project, we followed Pearson et al. $(2002,2003)$ in using a modified DIM that is based on entrainment rates directly measured in 2002 on the Corps dredge, Essayons, at particular locations in the Columbia River (Section 2.1.2). Entrainment rates for locations not sampled in 2002 were estimated using a site-specific ratio estimator (Section 2.1.3). The approach included the following steps (Figure 2):

1. Use entrainment rates ( $R$, as crab/cy) by age class.

2. Multiply the entrainment rates by the dredged volumes (cy) to give the number of crab entrained (E, as number of crab).

3. Apply the post-entrainment mortality rates from Wainwright et al. (1992) to give immediate losses.

4. Apply the natural survival rates from Wainwright et al. (1992) to give the AEL (as number of crab) to midwinter age 2+. (To obtain the AEL at age $2+$ for age $3+$ crab, the number of age $3+$ crab was back-calculated to its equivalent at age $2+$ using the reciprocal of the survival rate.) 
5. Apply a survival rate of $45 \%$ from midwinter age $2+$ to midwinter age $3+$ (Armstrong et al. 1987) to give the AEL at age 3+.

6. Apply observed sex ratios and a harvest rate of $70 \%$ (Wainwright et al. 1992) to give the LF (as number of crab).

7. Calculate the variance and $95 \% \mathrm{CI}$ for E, AEL, and LF.

The projected E, AEL at age 2+, AEL at age 3+, and LF were estimated for four locations over two construction dredging increments, detailed in Section 3.1.6.

Because we have no empirical data on entrainment rates for private contractor dredge efforts, it is assumed that entrainment rates would be similar to those observed with the Corps dredge, Essayons.

\subsubsection{Statistical Analyses and Calculation of Variance and Confidence Limits}

Methods for calculating associated variance and confidence limits follow the same guidelines outlined in Pearson et al. (2002, 2003), which we repeat below.

\section{Estimating Numbers of Entrained Crab}

In a random sample of loads, crab-entrainment densities were estimated from a random sample of dredged material. Hence, the sampling design consists of a two-stage sampling scheme: Stage 1-Random sample of $h$ of $H$ loads, and Stage 2-Random sample of dredged material based $b$ of $B$ basket samples. The estimator of total entrainment for a specific age class (i.e., size class) of crab can be expressed as follows:

$$
\hat{E}_{i}=\frac{\sum_{j=1}^{h}\left[\frac{V_{j}}{b_{j}} \sum_{l=1}^{b_{j}} x_{i j l}\right]}{\sum_{j=1}^{h} V_{j}} \cdot \sum_{j=1}^{H} V_{j}
$$

where

$$
\begin{aligned}
x_{i j l}= & \text { number of age class } i(i-1, \ldots, A) \text { crab/cy measured in the } l \text { th basket sample }\left(l-1, \ldots, b_{j}\right) \text { in } \\
& \text { the } j \text { th load }(j=1, \ldots, h) \\
b_{j}= & \text { number of basket samples observed in the } j \text { th load }(j=1, \ldots, h) \\
h= & \text { number of loads selected for sampling of crab density } \\
H= & \text { total number of loads at a dredged location } \\
V_{j}= & \text { total volume of dredged materials in the } j \text { th load }(j=1, \ldots, h) .
\end{aligned}
$$

In turn, $x_{i j l}$ can be expressed in terms of the number of crab counted and the volume of the $l$ th basket sample of the $j$ th load where

$$
x_{i j l}=\frac{c_{i j l}}{w_{j l}}
$$

where

$$
\begin{aligned}
c_{i j l}= & \text { number of age class } i \mathrm{crab}(i=1, \ldots, A) \text { in the } l \text { th basket sample }\left(l=1, \ldots, b_{i}\right) \text { in the } j \text { th load } \\
& (j=1, \ldots, h)
\end{aligned}
$$


$\begin{aligned} w_{j l}= & \text { volume of the material sampled in the } l \text { th basket sample }\left(l=1, \ldots, b_{i}\right) \text { in the } j \text { th load } \\ & (j=1, \ldots, h) .\end{aligned}$ As such, the estimator of total crab entrainment for age class $i$ crab $(i=1, \ldots, A)$ can be expressed as

$$
\hat{E}_{i}=\frac{\sum_{j=1}^{h}\left[V_{j} \frac{\sum_{l=1}^{b_{j}} c_{i j l}}{\sum_{l=1}^{b_{j}} w_{j l}}\right]}{\sum_{j=1}^{h} V_{j}} \cdot \sum_{j=1}^{H} V_{j} .
$$

Estimators (10) and (11) will be the same if sample values $w_{i j}=w_{i}$ are equal within a load. Because sample volumes varied between basket samples, estimator (11) is the preferred estimator of total entrainment.

The variance of $\hat{E}_{i}$ is found by taking the variance in stages. The variance of $\hat{E}_{i}$ (Equation 11) can then be expressed as follows:

$$
\operatorname{Var}\left(\hat{E}_{i} \mid E_{i}\right)=H^{2}\left(1-\frac{h}{H}\right) \frac{\sum_{j=1}^{H}\left(V_{j} R_{i j}-R_{i} V_{j}\right)^{2}}{h(H-1)}+\frac{H}{h} \sum_{j=1}^{H}\left[V_{j}^{2} \cdot \operatorname{Var}\left(\hat{R}_{i j}\right)\right]
$$

where

$R_{i j}=\frac{\sum_{l=1}^{B_{j}} c_{i j l}}{\sum_{l=1}^{B_{j}} w_{j l}}=$ true density of age class $i$ crabs (i.e., crabs $\left./ Y^{3}\right)$ in the $j$ th load $(j=1, \ldots, H)$;

$$
\begin{aligned}
R_{i} & \left.=\frac{\sum_{j=1}^{H} R_{i j} V_{j}}{\sum_{j=1}^{H} V_{j}}=\text { true density of crabs (i.e., crabs } / Y^{3}\right) \text { across all } H \text { levels; } \\
\operatorname{Var}\left(\hat{R}_{i j}\right) & =\frac{\left(1-\frac{b_{j}}{B_{j}}\right)}{b_{j} \bar{w}_{j}} \frac{\sum_{l=1}^{B_{j}}\left(c_{i j l}-R_{i j} w_{j l}\right)^{2}}{\left(B_{j}-1\right)}
\end{aligned}
$$

and where 
$\bar{w}_{j}=\frac{\sum_{l=1}^{B_{j}} w_{j l}}{B_{j}}=$ average volume of basket sample in the $i$ th load;

$B_{j}=$ total number of possible basket samples within the $j$ th load.

Variance formula (12) cannot be used to analyze the field data because it is dependent upon unknown parameter values. Instead, an estimated variance must be calculated and used in confidence interval (CI) estimates.

An approximately unbiased variance estimator for $\hat{E}$ can be written as follows:

$$
\widehat{\operatorname{Var}}\left(\hat{E}_{i} \mid E_{i}\right)=H^{2}\left(1-\frac{h}{H}\right) \frac{\sum_{j=1}^{h}\left(V_{j} \hat{R}_{i j}-\hat{R}_{i} V_{j}\right)^{2}}{(h-1)}+\frac{H}{h} \sum_{j=1}^{h} V_{j}^{2} \cdot \widehat{\operatorname{Var}}\left(\hat{R}_{i j}\right)
$$

where

$$
\begin{gathered}
\hat{R}_{i j}=\frac{\sum_{l=1}^{b_{j}} c_{i j l}}{\sum_{l=1}^{b_{j}} w_{j l}}, \\
\hat{R}_{i}=\frac{\sum_{j=1}^{h}\left[V_{j} \frac{\sum_{l=1}^{b_{j}} c_{i j l}}{\sum_{l=1}^{b_{j}} w_{j l}}\right]}{\sum_{j=1}^{h} V_{j}}, \\
\widehat{\operatorname{Var}}\left(\hat{R}_{i j}\right)=\frac{\left(1-\frac{b_{j}}{B_{j}}\right)}{b_{j} \bar{w}_{j}^{2}} \frac{\sum_{l=1}^{b_{j}}\left(c_{i j l}-\hat{R}_{i j} w_{j l}\right)^{2}}{\left(b_{j}-1\right)},
\end{gathered}
$$

which, when $B_{j}$ is very large, simplifies to

$$
\widehat{\operatorname{Var}}\left(\hat{R}_{i j}\right)=\frac{\sum_{l=1}^{b_{j}}\left(c_{i j l}-\hat{R}_{i j} w_{j l}\right)^{2}}{\bar{w}_{j}^{2} b_{j}\left(b_{j}-1\right)}
$$

and where 


$$
\bar{w}_{j}=\frac{\sum_{l=1}^{b_{j}} w_{j l}}{b_{j}} .
$$

Asymptotic (1- $\alpha) 100 \%$ CI estimates for $\hat{E}_{i}$ can be calculated as

$$
\hat{E}_{i} \pm Z_{1-\frac{\alpha}{2}} \sqrt{\widehat{\operatorname{Var}}\left(\hat{E}_{i} \mid E_{i}\right)}
$$

\section{Estimating the Entrainment Rate}

The entrainment rate $\left(R_{i}\right)$ for the $i$ th age class of crab can be defined by Equation (14) or equivalently as the ratio of the total number of crab entrained to the total volume of dredged material collected where

$$
R_{i}=\frac{E_{i}}{\sum_{j=1}^{H} V_{j}}
$$

The entrainment rate $\left(R_{i}\right)$ can be estimated by the ratio

$$
\hat{R}=\frac{\hat{E}_{i}}{\sum_{j=1}^{H} V_{j}}
$$

with associated variance estimator

$$
\widehat{\operatorname{Var}}\left(\hat{R}_{i} \mid R_{i}\right)=\frac{\widehat{\operatorname{Var}}\left(\hat{E}_{i} \mid E_{i}\right)}{\left[\sum_{j=1}^{H} V_{j}\right]^{2}}
$$

Estimating Adult Equivalent Loss (AEL)

The estimate of AEL for the Dungeness crab entrainment can be expressed as follows:

$$
\widehat{A E L}=\sum_{i=1}^{A} \hat{E}_{i} \cdot \hat{M}_{i} \cdot \hat{S}_{i}
$$

where

$$
\hat{E}_{i}=\text { estimate of total crab entrained of age class }(i=1, \ldots, A)
$$




$$
\begin{aligned}
\hat{M}_{i}= & \text { estimate of direct mortality associated with the dredging operation on crab entrained of } \\
& \text { age class } i(i=1, \ldots, A) \\
\hat{S}_{i}= & \text { estimate of the survival probability from age class } i(i=1, \ldots, A) \text { to age of interest } \\
A= & \text { number of age classes (i.e., age } 2+\text { or } 3+)
\end{aligned}
$$

Estimates of $\hat{M}_{i}$ and $\hat{S}_{i}$ used in the assessment did not have associated variance estimators. Hence, the contribution of $\operatorname{Var}\left(\hat{M}_{i}\right)$ and $\operatorname{Var}\left(\hat{S}_{i}\right)$ could not be propagated to the overall variance of the AEL

estimates. Instead, $\hat{M}_{i}$ and $\hat{S}_{i}$ were treated as known constants when calculating the variance of $\widehat{A E L}$. In which case,

$$
\widehat{\operatorname{Var}}(\widehat{A E L})=\sum_{i=1}^{A}\left[\operatorname{Var}\left(\hat{E}_{i} \mid E_{i}\right) \cdot \hat{M}_{i}^{2} \cdot \hat{S}_{i}^{2}\right]
$$

Equation (18) will underestimate the true variance of the AEL estimates when $\hat{M}_{i}$ and $\hat{S}_{i}$ are measured with error.

\section{Estimating Loss to Fishery (LF)}

The LF of harvestable crab was estimated by the quantity

$$
\widehat{L F}=\hat{H} \cdot \sum_{i=1}^{A} \hat{G}_{i} \hat{E}_{i} \hat{M}_{i} \hat{S}_{i}
$$

where

$$
\begin{aligned}
& \hat{G}_{i}=\text { estimated fraction of the } i \text { th age class composed of males } \\
& \hat{H}=\text { estimated probability of harvesting a male crab in the Dungeness fishery. }
\end{aligned}
$$

Again, assuming the values of $\hat{G}_{i}$ and $\hat{H}$ are known constants, the variance of $\widehat{L F}$ can be estimated by the formula

$$
\widehat{\operatorname{Var}}(\widehat{L F})=\hat{H}^{2} \cdot \sum_{i=1}^{A}\left[\widehat{\operatorname{Var}}\left(\hat{E}_{i} \mid E_{i}\right) \cdot\left(\hat{G}_{i} \cdot \hat{M}_{i} \cdot \hat{S}_{i}\right)^{2}\right]
$$

Equation (20) will underestimate the true variance of $\widehat{L F}$ when and $\hat{H}$ and $\hat{G}_{i}$ are measured with error.

\subsection{Crab Salinity Model}

The 2002 and 2004 field sampling included paired measurements of entrainment rates and bottom salinity that formed the basis for the crab salinity model (Pearson et al. 2002, 2003, and this report). Regression analysis similar to that of Pearson et al. (2002) used the paired observations from both 2002 and 2004 samplings. 


\subsection{Application of Crab Salinity Model}

To assess how entrainment rates vary with seasonal salinity regimes in the CRE, we applied the crab salinity model to bottom salinity data from two stations (RED26 and AM169) in the Environmental Observation and Forecasting System (EOFS) for the COlumbia RIver Estuary (CORIE), an environmental sensor network through the Oregon Graduate Institute. RED 26 is near Desdemona Shoals, whereas AM169 is at the Astoria Bridge between Flavel Bar and Upper Sands (Figure 1). Dr. Shyam Nair of E2 Consulting Engineers, Inc., constructed a cumulative frequency distribution of the bottom salinity values from CORIE stations in the LCR from 1996 to 2003. From Dr. Nair's cumulative distribution function, we compiled by month the proportion of salinity observations less than 16 psu from stations RED26 and AM169 for 2001 to 2003, the years for which bottom salinity data was available.

To calculate how the AEL and LF could vary by season, we used the entrainment rates developed above with the modified DIM model to calculate the AEL and LF following the approach presented in Pearson et al. (2002, 2003). The input value for the dredged volume was established at 60,000 cy, a value approximately equivalent to a day's dredging by the Corps Dredge, Essayons.

The entrainment rates estimated from the regression equation are from projections rather than from direct field measurements. Therefore, the variances to be used in the modified DIM need to be calculated in a different manner than that used above. The approach to estimate variances for projections for ages $2+$ and $3+$ crab was developed as follows:

A log-linear model of the form

$$
y_{i}=\alpha+\beta x_{i}
$$

was constructed where $y_{i}$ is a log-transformed observation. The objective is to make a projection on the arithmetic scale such that

$$
\hat{\theta}=e^{\hat{\alpha}+\hat{\beta} x_{i}} \text {. }
$$

It is further noted that $x_{i}$ used in the projection will be an estimate of some $\hat{\mu}$ salinity value, such that

$$
\hat{\theta}=e^{\hat{\alpha}+\hat{\beta} \hat{\mu}} \text {. }
$$

The aim is a variance estimate for $\hat{\theta}[$ i.e., $\widehat{\operatorname{Var}}(\hat{\theta})]$.

For convenience, let

$$
\hat{y}=\hat{\alpha}+\hat{\beta} \hat{\mu}
$$

be the projected value on the log-scale when the independent variable is $\hat{\mu}$. Using the delta method,

$$
\widehat{\operatorname{Var}}(\hat{\theta})=\widehat{\operatorname{Var}}\left(e^{\hat{y}}\right) \doteq \widehat{\operatorname{Var}}(\hat{y})\left(e^{2 \hat{y}}\right) \text {. }
$$

In turn, the variance of $\hat{y}$ can be calculated in stages using the conditional variance law: 


$$
\begin{aligned}
\operatorname{Var}(\hat{y}) & =\operatorname{Var}_{\hat{\mu}}[E(\hat{y} \mid \hat{\mu})]+E_{\hat{\mu}}[\operatorname{Var}(\hat{\mathrm{y}} \mid \hat{\mu})] \\
& =\operatorname{Var}_{\hat{\mu}}[\alpha+\beta \hat{\mu}]+E_{\hat{\mu}}\left[\operatorname{MSE}\left(1+\frac{1}{n}+\frac{(\hat{\mu}-\bar{x})^{2}}{\sum_{i=1}^{n}\left(x_{i}-\bar{x}\right)^{2}}\right)\right] \\
& =\beta^{2} \operatorname{Var}(\hat{\mu})+\operatorname{MSE}\left(1+\frac{1}{n}+\frac{E(\hat{\mu}-\bar{x})^{2}}{\sum_{i=1}^{n}\left(x_{i}-\bar{x}\right)^{2}}\right) \\
\operatorname{Var}(\hat{y}) & =\beta^{2} \operatorname{Var}(\hat{\mu})+\operatorname{MSE}\left(1+\frac{1}{n}+\frac{\operatorname{Var}(\hat{\mu})+(\mu-\bar{x})^{2}}{\sum_{i=1}^{n}\left(x_{i}-\bar{x}\right)^{2}}\right) .
\end{aligned}
$$

This variance can be estimated by the expression:

$$
\widehat{\operatorname{Var}}(\hat{y})=\hat{\beta}^{2} \widehat{\operatorname{Var}}(\hat{\mu})+\operatorname{MSE}\left(1+\frac{1}{n}+\frac{\widehat{\operatorname{Var}}(\hat{\mu})+(\hat{\mu}-\bar{x})^{2}}{\sum_{i=1}^{n}\left(x_{i}-\bar{x}\right)^{2}}\right) .
$$

Combining equation (24) and equation (25) yields

$$
\widehat{\operatorname{Var}}(\hat{\theta})=\left[\hat{\beta}^{2} \cdot \widehat{\operatorname{Var}}(\hat{\mu})+\operatorname{MSE}\left(1+\frac{1}{n}+\frac{\widehat{\operatorname{Var}}(\hat{\mu})+(\hat{\mu}-\bar{x})^{2}}{\sum_{i=1}^{n}\left(x_{i}-\bar{x}\right)^{2}}\right)\right] \cdot e^{2 \hat{y}},
$$

where

$$
\begin{aligned}
\hat{\beta} & =\text { estimated slope term in the linear model, } \\
n & =\text { number of observations used in constructing the regression model, } \\
\text { MSE } & =\text { error mean square that comes from the ANOVA table used in developing the regression } \\
& \text { model, } \\
x_{i} & =\text { the } i \text { th }(i=1, \ldots, n) \text { independent observation used in developing the regression model, } \\
\bar{x} & =\frac{\sum_{i=1}^{n} x_{i}}{n}=\text { mean value of the independent observations used in developing the regression } \\
\hat{\mu} & =\text { estimated multi-year salinity value used in the projection, } \\
\operatorname{Var}(\hat{\mu}) & =\frac{s^{2}}{m}=\text { variance in the multi-year salinity value used in the projection, }
\end{aligned}
$$

and where,

$$
\frac{\sum_{i=1}^{n}\left(z_{i}-\hat{\mu}\right)^{2}}{m-1}=\text { sample variance in salinity }
$$




$$
\begin{aligned}
z_{i}= & i \text { th value going into the multi-year mean, } \\
m= & \text { number of values used to calculate the mean } \hat{\mu} \\
& (\text { nominally } m=5) \\
\hat{\mu}= & \frac{\sum_{i=1}^{m} z_{i}}{m} .
\end{aligned}
$$

An asymptotic $95 \%$ CI for $\hat{\theta}$ would be calculated as

$$
\hat{\theta} \pm t_{n-2} \sqrt{\widehat{\operatorname{Var}}(\hat{\theta})}
$$

where $t_{n-2}$ is a t-statistic with $n-2$ degrees of freedom at $\alpha=0.05$, two-tailed. 


\subsection{RESULTS}

\subsection{Crab-Entrainment Rates and Projected Losses}

\subsubsection{Field Sampling Effort}

Biologists made direct measurements of crab-entrainment rates aboard the Corps Dredge, Essayons, during August and September 2004. Sampling was conducted at Flavel Bar, Desdemona Shoals, and the MCR while the dredge was conducting maintenance dredging of the navigation channel. A total of 270 basket samples were taken from 91 loads, distributed by location as follows: Flavel Bar, 30 loads; Desdemona Shoals, 18 loads; MCR, 43 loads (Table 2).

\subsubsection{Measured 2004 Entrainment Rates}

Dungeness crab were found in dredge entrainment samples from all field locations throughout the course of the 2004 sampling effort (Table 3). Other species entrained in moderate numbers included Crangon shrimp, razor clams (Siliqua patula), Pacific sandlance (Ammodytes hexapterus), staghorn sculpin (Leptocottus armatus), and Northern anchovy (Engraulis mordax).

The total entrainment rate for all Dungeness crab age classes (combined) ranged from $0.011 \mathrm{crab} / \mathrm{cy}$ at Flavel Bar to $0.094 \mathrm{crab} / \mathrm{cy}$ at MCR (Table 4). Samples at Flavel Bar were composed of small numbers but relatively equal proportions of ages $1+, 2+$, and $3+$ crab, whereas age $0+$ crab were not collected. At Desdemona Shoals, ages $0+, 2+$, and $3+$ crab were represented in entrainment samples, but age $1+$ crab were not collected. At MCR, age 0+ crab predominated in entrainment samples made during every 2004 sampling period, although all other age classes were also represented at this location. In general, crabentrainment rates (by age class) were relatively consistent during each of the three MCR sampling periods.

\subsubsection{Review of Measured 2002 Entrainment Rates}

At upriver sites in 2002, the total entrainment rates for all crab age classes (combined) ranged from $0.000 \mathrm{crab} / \mathrm{cy}$ at Miller Sands to $0.224 \mathrm{crab} / \mathrm{cy}$ at Desdemona Shoals in June (Pearson et al. 2002) (Table 5). Entrainment samples at Desdemona Shoals in June 2002 were largely composed of age 1+ crab, whereas age $2+$ crab predominated September 2002 samples. At Upper Sands, only age 0+ and age $1+$ crab were observed in samples.

Over the course of all sampling periods in the MCR, total entrainment rates for all crab age classes were $0.060 \mathrm{crab} / \mathrm{cy}$ (Pearson et al. 2003) (Table 5). Age 2+ crab were entrained at the highest rate $(0.032 \mathrm{crab} / \mathrm{cy})$, whereas age $0+$ crab were entrained at the lowest rate $(0.003 \mathrm{crab} / \mathrm{cy})$ of all age classes. Of the six sampling periods, sampling Period 5 in October, which only encompassed three loads (Table 2), showed the highest entrainment rates $(0.179 \mathrm{crab} / \mathrm{cy})$. Total entrainment rates in the other five sampling periods reflected a much narrower range, from $0.049 \mathrm{crab} / \mathrm{cy}$ to $0.066 \mathrm{crab} / \mathrm{cy}$.

\subsubsection{Comparison Between 2002 and 2004 Entrainment Rates}

Interannual comparisons of entrainment rates were location-specific and limited to approximately the same sampling dates in 2002 and 2004 (Table 6). To compare MCR data collected from August 21 through September 16, 2004 ("2004 MCR All”, Table 2), a subset of information collected during the third 2002 sampling effort (August 24 through September 16) (“2002 MCR - 3"; Table 2) was used. For Desdemona Shoals, we limited our comparisons of data collected during August 21 through August 24, 
2004 (“2004 Desdemona”; Table 2) to data collected in September 2002 (“2002 Desdemona - 2”; Table 2).

For both locations, mean entrainment rates of age 0+ crab were higher in 2004 versus 2002 (Table 6, Figure 3). Entrainment rates of all other age classes were lower in 2004 than 2002. In 2004, crabentrainment rates for most age classes were highest at MCR, lowest at Flavel Bar, and at some intermediate level at Desdemona Shoals. In general, variance terms were much higher for data collected in 2002 at Desdemona Shoals compared with other locations and years.

\subsubsection{Interannual-Entrainment-Rate Ratio Estimate}

Separate estimates of Dungeness crab entrainment rates at Flavel Bar in 2002 were calculated for each age class (ages 0+, 1+, 2+, and 3+) using 2002 and 2004 MCR and Desdemona data and 2004 Flavel Bar data (Table 7). To account for the variance associated with the original data, a weighted average, as opposed to an arithmetic average, of the site-specific estimates was used to derive the final Flavel Bar 2002 entrainment rate and variance estimates. Tight variance associated with MCR data, therefore, was weighted more heavily than that for the Desdemona data in the final Flavel Bar estimates.

The entrainment rate estimate of age $0+$ crab at Flavel Bar in 2002 was 0.0 crab/cy because no crab were observed there in 2004 (Table 7, Figures 4 and 5). The estimate of age 1+ crab at Flavel Bar in 2002 was $0.0037 \mathrm{crab} / \mathrm{cy}$, which was slightly higher than 2004 Flavel Bar values because of the higher numbers of age 1+ crab observed at MCR in 2002 compared with 2004 rates. Entrainment-rate estimates of age 2+ crab (0.0054 crab/cy) and age 3+ crab (0.0053 crab/cy) at Flavel Bar in 2002 were also slightly higher than 2004 rates for the same reason.

\subsubsection{Dredge Impact Model - Estimating Adult Equivalent Loss and Loss to Male Fishery from Channel Deepening}

The Columbia River Channel Improvement Project involves construction dredging at four locations between RM3 and RM20: Desdemona Shoals (RM4 to RM9), Flavel Bar (RM10 to RM13), Upper Sands (RM14 to RM17), and Tongue Point (RM18 to RM20) (Table 8). Estimated dredged materials volumes were provided by the Corps for these locations under two future construction increments (Tables 8 and 9): 1) dredging to $40 \mathrm{ft}$, and 2) dredging from $40 \mathrm{ft}$ to $43 \mathrm{ft}$.

Crab entrainment, AEL at age 2+, AEL at age 3+, and LF were projected using the following locationbased entrainment rates:

$\begin{array}{lll}\text { Location } & \text { Source } & \text { Entrainment Rate (R) Data } \\ \text { Desdemona Shoals } & \text { Measured on location, Sept 2002 } & \text { 2002 Desdemona-2 (Table 5) } \\ \text { Flavel Bar } & \text { Ratio estimate, 2002 and 2004 data } & \text { Weighted average (Table 7) } \\ \text { Upper Sands } & \text { Measured on location, 2002 } & \text { 2002 Upper Sands (Table 5) } \\ \text { Tongue Point } & \text { Used adjacent downriver location, 2002 } & \text { 2002 Upper Sands (Table 7) }\end{array}$

The results of construction dredging projections are detailed in Table 10 (Dredging to $40 \mathrm{ft}$ ) and Table 11 (Dredging from $40 \mathrm{ft}$ to $43 \mathrm{ft}$ ), and summarized with 95\% confidence limits in Table 12. In general, adult crab losses are projected to decline as dredging moves from downriver to upriver locations. The lowest projected AEL and LF values were observed at Tongue Point (using Upper Sands entrainment rates), whereas the highest projected AEL and LF values were observed at Desdemona Shoals. These results can be attributed to a combination of lower entrainment rates and declining dredging volumes (at least for the 40- to 43-ft increment) at upriver locations. 
For example, projections at the 40-ft construction increment for AEL of age 2+ crab range from $34 \mathrm{crab}$ (95\% CI of 0 to $102 \mathrm{crab}$ ) at Tongue Point to $59,818 \mathrm{crab}(95 \%$ CI of 36,076 to $83,560 \mathrm{crab}$ ) at Desdemona Shoals (Tables 10 and 12). Similarly, projected LF levels for this construction increment range from $6 \mathrm{crab}(95 \% \mathrm{CI}$ of 0 to $17 \mathrm{crab})$ at Tongue Point to 9,422 crab (95\% CI of 5,683 to 13,161 crab) at Desdemona Shoals.

Projections at the 40- to 43-ft construction increment for AEL of age 2+ crab range from $462 \mathrm{crab}$ ( $95 \%$ $\mathrm{CI}$ of 0 to $1,350 \mathrm{crab}$ ) at Tongue Point to $47,738 \mathrm{crab}$ (95\% CI of 28,790 to 102,614 crab) at Desdemona Shoals (Tables 11 and 12). Projected LF for this construction increment range from $73 \mathrm{crab}$ (95\% CI of 0 to $213 \mathrm{crab})$ at Tongue Point to 7,519 crab (95\% CI of 4,535 to 10,503 crab) at Desdemona Shoals.

The projected AEL of age 2+ crab from both increments of construction dredging range from 64,866 crab to 201,600 crab (Table 12). Overall projected LF from construction dredging range from 10,218 to $31,753 \mathrm{crab}$.

\subsection{Salinity Model}

The results of the regression analysis using both 2002 and 2004 data are essentially the same as those found previously by Pearson et al. (2002, 2003). The proportion of salinity observations less than $16 \mathrm{psu}$ remains the variable explaining the highest percentage of the variance. The regressions for entrainment rates of ages $0+$ and $1+$ crab against bottom salinity were not significant (Table 13). The regression analysis produced significant log-linear equations that relate the entrainment rates $(\mathrm{R})$ for ages $2+$ and $3+$ $\mathrm{crab}$ to the proportion of salinity observations less than $16 \mathrm{psu}$. The log-linear equations for ages $2+$ and $3+$ crab were not significantly different from one another, so that the data were pooled to produce a single regression equation for both age classes:

$$
\mathrm{R}=\mathrm{e}^{[-4.15095+(-5.79916 * \text { salinity })]}
$$

with an R-squared of $86 \%$ (Figure 6).

\subsection{Application of Crab Salinity Model}

Bottom salinity observations were available from CORIE stations RED26 and AM169 in most months from 2001 to 2003 (Tables 14 and 15). Using the cumulative frequency distribution values compiled from this dataset, we calculated the total monthly proportion of salinity observations less than $16 \mathrm{psu}$ (Tables 16 and 17).

These monthly salinity values were used in regression equation (27) to estimate the monthly entrainment rates of ages $2+$ and $3+$ crab at two stations in the LCR (Figures 7 and 8). Because there was no significant regression equation for ages $0+$ and $1+$ crab, we relied upon mean entrainment rates from upriver locations in the estuary (but not the MCR) measured in 2002 and 2004, and applied this rate equally to all months (Tables 16 and 17).

For AM169 at the Astoria Bridge near Flavel Bar and Upper Sands, the percentage of the bottom salinity observations less than 16 psu was over 70\% from January through June of the years 2001 through 2003 and was about 50\% from July through November (Figure 7, Table 16). Estimated entrainment rates using the AM169 salinity data are less than $0.0005 \mathrm{crab} / \mathrm{cy}$ from December through June and about $0.001 \mathrm{crab} / \mathrm{cy}$ from July through November. For RED26 on the southern side of the navigation channel near Desdemona Shoals, the percentage of the bottom salinity observations less than 16 psu was over 
50\% from December through June during 2001 through 2003 and was about 30\% from July through November (Figure 8, Table 17). Estimated entrainment rates using the RED26 salinity data are about $0.001 \mathrm{crab} / \mathrm{cy}$ from December through June and about 0.0025 to $0.0034 \mathrm{crab} / \mathrm{cy}$ from July through November.

For a dredged volume of 60,000 cy (which is approximately 10 loads, or one day's dredging, for the Corps Dredge, Essayons), the predicted AEL and LF show the same seasonal pattern as the entrainment rates (Tables 18 and 19, Figures 9 through 11). For monthly salinity data from both stations, the forecast AEL and LF are lower from December to June than from July to November. The forecast AEL and LF for the AM169 salinity data are lower than those for RED26 salinity data. 


\subsection{DISCUSSION}

\subsection{Entrainment and Losses}

The 2004 sampling fulfilled its first objective by providing direct measurements of entrainment rates at Flavel Bar, which had not been sampled in 2002. These measured entrainment rates enabled an assessment of whether entrainment rates at Flavel Bar are more similar to those of Upper Sands or to those of Desdemona Shoals. The direct measurements in 2004 indicate that entrainment rates at Flavel Bar are indeed more similar to those at Upper Sands (Figure 3). The salinity regimes at Flavel Bar are fresher than those at Desdemona Shoals and are thus more similar to the other upriver locations. The bottom salinity values measured with the entrainment rates averaged 13.31 at Upper Sands, 20.0 psu at Flavel Bar, 26.1 psu at Desdemona Shoals, and 28 to 32 psu in the MCR (Table 3). For the summer months from 2001 to 2003, the percentages of bottom salinity observations less than 16 psu were about $50 \%$ for CORIE Station AM169 near Flavel Bar and about 30\% for CORIE Station RED26 near Desdemona Shoals (Figures 7 and 8).

The entrainment rates varied by dredging location, age class, and year. The entrainment rates from both 2002 and 2004 decreased substantially moving from the MCR and Desdemona Shoals to the other upriver locations. In 2002, the entrainment rates for all age classes were $0.0603 \mathrm{crab} / \mathrm{cy}$ in the MCR, 0.2240 $\mathrm{crab} / \mathrm{cy}$ at Desdemona Shoals in June, $0.1190 \mathrm{crab} / \mathrm{cy}$ at Desdemona Shoals in September, $0.0210 \mathrm{crab} / \mathrm{cy}$ at Upper Sands, and zero at Miller Sands. In 2004, the entrainment rates for all age classes were 0.0937 crab/cy in the MCR, $0.0239 \mathrm{crab} / \mathrm{cy}$ at Desdemona Shoals, and $0.0112 \mathrm{crab} / \mathrm{cy}$ at Flavel Bar.

Comparing entrainment rates for all age classes by year, the rates for the MCR increased by $55 \%$ from 2002 to 2004, whereas those for Desdemona decreased by 76\% from September 2002 to August 2004. For the MCR, the majority of the difference between 2002 and 2004 derived from an increase in 2004 of the age $0+$ crab, which are known to vary substantially among years and episodically within a year. For Desdemona Shoals, the June 2002 entrainment rate for age $1+$ crab $(0.1930 \mathrm{crab} / \mathrm{cy})$ was the highest in the entire data set, whereas the August 2004 entrainment rate for age 1+ crab (zero crab/cy) was tied for the lowest in the data set.

The 2002 and 2004 field data suggest the following:

- The upriver locations (Flavel Bar, Upper Sands, Tongue Point, and Miller Sands) were dominated more by fresh than salt water. The locations from Flavel Bar and upriver had entrainment rates for all age classes that were consistently low (below $0.02 \mathrm{crab} / \mathrm{cy}$ ) and became zero when freshwater occurred at the bottom most of the time.

- The MCR was dominated by oceanic water with bottom salinities above 28 psu for $98 \%$ of the observations during the summer sampling period. The MCR had entrainment rates that were consistently between 0.05 and $0.10 \mathrm{crab} / \mathrm{cy}$ and reaching $0.18 \mathrm{crab} / \mathrm{cy}$ for one sampling period.

- Desdemona Shoals had bottom salinities intermediate between those of the MCR and the upriver locations. Desdemona Shoals had the most variable entrainment rates ranging from 0.02 to 0.22 $\mathrm{crab} / \mathrm{cy}$.

The dynamics behind the variable entrainment rates at Desdemona Shoals are not fully understood but appear to involve age $1+$ crab. The entrainment rates for ages $2+$ and $3+$ crab in the MCR and at Desdemona vary over comparable ranges within and between years (Tables 4 to 6). In the MCR, entrainment rates for age $1+$ crab are consistently about an order of magnitude lower than those for ages $2+$ and $3+$ crab. At Desdemona Shoals, entrainment rates for age 1+ crab vary from the lowest to the highest in the data set, and in June 2002, were higher than those for ages $2+$ and $3+$ crab. In the 
regression analysis for entrainment rates as a function of bottom salinity, the regression for age $1+$ crab was not significant. Apparently, factors other than salinity may be influencing distribution and entrainment rates for age $1+$ crab. One possibility might be predation on age $1+$ crab by older crab. Another could be the seasonal movements of age $1+$ crab. The route by which age $1+$ crab enter the estuary in the spring is not known.

Because of the patterns in mortality among age classes, the contribution from the age $2+$ and $3+$ crab heavily dominates the total AEL projections. Because of the high mortality to which age $0+$ crab are subjected, age 0+ crab typically make little contribution to the AEL. For the MCR in 2002, the contribution of age $0+$ crab to the total AEL both at age 2+ and 3+ was less than $0.01 \%$ (Pearson et al. 2003). Age 1+ crab are subject to less mortality than age $0+$ crab. For the MCR in 2002, the contribution of age $1+$ crab to the total AEL both at age 2+ and 3+ was about 3.5\% (Pearson et al. 2003). For Desdemona Shoals in 2002, the contributions of the age 1+ crab to the AEL at ages $2+$ and $3+$ were about 45\% with the June 2002 entrainment rates, and about 2\% with the September 2002 rates (Pearson et al. 2002).

The 2004 data enabled the forecasting of the AEL and LF at Flavel Bar based on data specific to that location rather than from adjacent locations, thereby avoiding the overestimates or underestimates discussed in Pearson et al. (2002, 2003). As an example, Pearson at al. (2002) estimated the values for the AEL of age 2+ crab at Flavel Bar from construction dredging to $40 \mathrm{ft}$ to be $11,008 \mathrm{crab}$ using June 2002 Desdemona rates, 27,317 crab using September 2002 Desdemona rates, and 270 crab using Upper Sands rates (Pearson et al. 2002). Our use here of the 2002 rates for Flavel Bar hindcast by ratio estimation from the 2004 data provides an estimated value of 3,682 crab for the AEL at age 2+ (Table 10).

The additional sampling in 2004 improved the estimates of loss from entrainment associated with the Columbia River Channel Improvement Project in two ways. First, the estimates for Flavel Bar are now based on site-specific data rather than extrapolated from adjacent areas. Second, the additional 2004 data led to reduced variance and narrower confidence limits. For the combined construction dredging (to $40 \mathrm{ft}$ and from $40 \mathrm{ft}$ to $43 \mathrm{ft}$ ), Pearson et al. (2002) forecasted the $95 \%$ confidence limits for the worst-case estimates for AEL at age 2+ to be $38,811 \mathrm{crab}$ to $281,528 \mathrm{crabs}$ and for the LF to be 7,252 crab to 44,342 crab. With the site-specific entrainment rates at Flavel Bar and the same dredged volumes used by Pearson et al. (2002) for the combined construction increments, we now forecast the $95 \%$ confidence limits to be $64,886 \mathrm{crab}$ to $201,600 \mathrm{crab}$ for the AEL at age $2+$ and 10,218 to $31,753 \mathrm{crab}$ for the LF (Table 12).

There are no population estimates available against which to judge the AEL at ages $2+$ and $3+$. However, the commercial crab landings from the regions adjacent to the Columbia River enable a comparison based on LF values. The 10-year average annual crab landings from the Washington and Oregon regions around the Columbia River are 5.3 million crab. The upper 95\% confidence limit for the loss to the male fishery forecast from the 2002 and 2004 data is less than $0.6 \%$ of the 10-year average annual commercial crab landings from the regions in and around the Columbia River.

\subsection{Crab Salinity Model}

The 2004 data enabled further elaboration of the crab salinity model for crab occurring in the MCR and South Channel of the estuary. The main feature of the model remains the same, i.e., the natural logarithms of the entrainment rates for ages $2+$ and $3+$ crab (but not for ages $0+$ and $1+$ crab) are significantly related to the proportion of bottom salinity observations less than $16 \mathrm{psu}$ (Figure 6). The finding that the regression equations for age $2+$ crab alone and age $3+$ crab alone do not differ significantly suggests that older age classes are responding to salinity in the same way (Table 13). The 
results indicate that the entrainment of the ages $0+$ and $1+$ crab are governed by factors in addition to or other than salinity. The results also indicate that factors other than bottom salinity influence entrainment of older crab when salinity approaches oceanic values (above $32 \mathrm{psu}$ ). As the salinity decreases from oceanic values, the entrainment rates for ages $2+$ and $3+$ crab decrease exponentially. The model predicts that in areas where salinity observations are lower than 16 psu at least $50 \%$ of the time (e.g., the summer salinity values near the Astoria Bridge), entrainment rates will be a fraction (less than 6\%) of those where salinity remains below 16 psu only $2 \%$ of the time (e.g., the summer values in the MCR).

The entrainment rates upon which the model was based were taken in the summer and fall months of 2002 and 2004 when the salinity intrusion is the highest in the yearly cycle. Therefore, extrapolating these rates to the winter and spring when salinity intrusion is the lowest leads to conservative predictions of rates for winter and spring.

\subsection{Application of Crab Salinity Model}

The crab salinity model was applied to forecast monthly entrainment rates from a 3-year record of bottom salinity measurements at two CORIE stations, AM169 and RED26. AM169 is at the Astoria Bridge and close to the upriver end of the Flavel Bar dredging reach. RED26 is at RM7 on the south side of the navigation channel and near Desdemona Shoals. These two stations are the only CORIE stations within the estuary for which bottom salinity records are available. The 3-year data sets are missing data from several months within any one year, but over the 3 years, there are data from each month of the year (Table 14 and 15). The two stations, RED 26 and AM169, act as surrogates, respectively, for Desdemona Shoals and for Flavel Bar and the upriver locations.

There is a seasonal pattern to the salinity regimes and thus to the entrainment rates for age $2+$ and $3+$ crab. Bottom salinity at AM169 is almost completely dominated by freshwater from December through June and dominated by freshwater even in summer and fall (July through November) (Figure 7). Predicted age 2+ and 3+ crab-entrainment rates for the AM169 data are very low in winter and spring (less than $0.0005 \mathrm{crab} / \mathrm{cy}$ ) and low in the summer and fall (about $0.001 \mathrm{crab} / \mathrm{cy}$ ). These predicted rates for AM169 are less than $1 \%$ and less than $10 \%$ of the average entrainment rates directly measured in the MCR during the summer of 2002 (the lower rate of the two years). RED26 near Desdemona Shoals has salinity regimes intermediate between the MCR and other river locations (Figure 8) but with same seasonal patterns (more saline from July through November). Predicted age $2+$ and $3+$ crab-entrainment rates from the RED26 data are less than $0.0015 \mathrm{crab} / \mathrm{cy}$ in the winter and spring and from 0.0025 to $0.0035 \mathrm{crab} / \mathrm{cy}$ in the summer and fall. The highest predicted rate from the RED26 data is about 0.0035 crab/cy in July. For both RED26 and AM169, the predicted winter/spring entrainment rates for age 2+ and $3+$ crab are about half of the predicted summer/fall entrainment rates.

Predictions for entrainment rates at Desdemona Shoals are complicated by the observations of higher entrainment rates for age $1+$ crab in June 2002, by the finding that age $1+$ crab-entrainment rates are not significantly related to bottom salinity, and by the high variability in the entrainment rates measured at Desdemona Shoals. Because the relative contribution of age 1+ crab to the total AEL is much smaller than those of the age $2+$ and $3+$ crab, higher age $1+$ crab-entrainment rates do not necessarily lead to higher losses. A higher loss was estimated using the September 2002 measured rates at Desdemona Shoals than in using the June 2002 rates, because the rates for age $2+$ and $3+$ crab were higher in September 2002 (Pearson et al. 2002).

The AEL and LF projections are a function of the entrainment rates by age class and the dredged volume. Therefore, because the projections of AEL and LF use a constant dredged volume of 60,000 cy, the seasonal patterns predicted from the crab salinity model show seasonal patterns similar to those for the predicted entrainment rates. Also, because average entrainment rates are used for the ages $0+$ and $1+$ 
crab, the seasonal patterns in entrainment rates and loss predictions are determined by the salinity responses of age $2+$ and $3+$ crab. As discussed above, ages $0+$ and $1+$ crab typically contribute only a small percentage to the predicted total AEL values.

The losses (AEL and LF) predicted for 60,000 cy averaged less in the winter/spring than in the summer/fall. For the AM169 data, predicted values for the AEL at age 2+ were $256 \mathrm{crab}$ for December through June and $373 \mathrm{crab}$ from July through November (Figure 10). For the RED26 data, predicted values for the AEL at age 2+ were $362 \mathrm{crab}$ for December through June and $636 \mathrm{crab}$ from July through November (Figure 11). The difference in predicted values for the AEL at age $2+$ between summer/fall and winter/spring was greater for RED26 (43\% decrease) than for AM169 (31\% decrease). This application of the crab salinity model indicates that adjusting the timing of dredging has potential to reduce crab losses. 


\subsection{REFERENCES}

Armstrong, David A., T. C. Wainwright, J. Orensanz, P. A. Dinnel, and B. R. Dumbauld. 1987. Model of Dredging Impact on Dungeness Crab in Grays Harbor, Washington. Fisheries Research Institute, University of Washington, School of Fisheries; FRI-UW-8702.

Brown, A.C., and N.B. Terwilliger. 1992. "Developmental changes in ionic and osmotic regulation in the Dungeness crab, Cancer magister." Biological Bulletin 182:270-277.

Brown, A.C., and N.B. Terwilliger. 1999. "Developmental changes in oxygen uptake in Cancer magister (Dana) in response to changes in salinity and temperature." Journal of Experimental Marine Biology and Ecology 241:179-192.

Larson, Kim W. 1993. Entrainment of Dungeness Crab by Hopper Dredge at the Mouth of the Columbia River, OR and WA. U.S. Army Corps of Engineers, Portland District; 1993.

McCabe, G. T. Jr., R. L. Emmett, T. C. Coley, and R. J. McConnell. 1986. Distribution, abundance, and size-class structure of Dungeness crab in the Columbia River Estuary. National Marine Fisheries Service, 2725 Montlake Boulevard East, Seattle, WA. Final Report to Portland District, U.S. Army Corps of Engineers, Contract DACW57-84-F-0178. 57 pp.

McCabe, G. T. Jr., and R. J. McConnell. 1989. Abundance and size-class structure of Dungeness crab in our near frequently dredged areas in the Columbia River estuary. National Marine Fisheries Service, 2725 Montlake Boulevard East, Seattle, WA. Report to Portland District, U.S. Army Corps of Engineers, P.O. Box 2946, Portland, OR 97208-2946. 22 pp.

McGaw, I.J., and B.R. McMahon. 1996. "Cardiovascular responses resulting from variation in external salinity in the Dungeness crab, Cancer magister." Physiological Zoology. 69:1384-1401.

McGaw, I.J., C.L. Reiber, and J.A. Guadagnoli. 1999. "Behavioral physiology of four crab species in low salinity." Biological Bulletin 196:163-176.

Pearson, W.H., G.D. Williams, and J.R. Skalski. 2002. Estimated Entrainment of Dungeness Crab During Dredging for the Columbia River Channel Improvement Project. PNNL-14129. Prepared for the U.S. Army Corps of Engineers, Portland District, by Battelle Marine Sciences Laboratory, Sequim, Washington. Published by Pacific Northwest National Laboratory, Richland, Washington.

Pearson, W.H., G.D. Williams, and J.R. Skalski. 2003. Estimated Entrainment of Dungeness Crab During Maintenance Dredging of the Mouth of the Columbia River, Summer 2002. PNNL-14190. Prepared for the U.S. Army Corps of Engineers, Portland District, by Battelle Marine Sciences Laboratory, Sequim, Washington. Published by Pacific Northwest National Laboratory, Richland, Washington.

Rooper, C.N, D.A. Armstrong, and D.R. Gunderson. 2002. "Habitat Use by Juvenile Dungeness Crab in Coastal Nursery Estuaries." Crab in Cold Water Regions: Biology, Management, and Economics. Alaska Sea Grant College Program, Publication AK-SG-02-01. pp. 609-629.

Stevens, B.G, and D.A. Armstrong. 1984. "Distribution, abundance, and growth of juvenile Dungeness crabs, Cancer magister, in Grays Harbor estuary, Washington." Fishery Bulletin 82:469-483.

Tasto, R.N. 1983. "Juvenile Dungeness crab, Cancer magister, studies in the San Francisco Bay area." In P.W. Wild and R.N Tasto (eds) Life History, Environment and Mariculture Studies of the Dungeness Crab, Cancer magister, with Emphasis on the Central California Fishery Resource. Fish Bulletin 172 of the Department of Fish and Game, State of California. pp. 135-154. 
Wainwright, T.C., D.A. Armstrong, P.A. Dinnel, J.M. Orensanz, and K.A. McGraw. 1992. "Predicting the effects of dredging on a crab population: An equivalent adult loss approach." Fishery Bulletin 90:171-182.

Wainwright, T.C.; K.A. McGraw, D.A. Armstrong, B.R. Dumbauld, and L.L. Conquest. 1990. Impact of Dredging on Dungeness crab, Cancer magister, in Grays Harbor, Washington, during August 1989. Fisheries Research Institute, University of Washington, School of Fisheries; 1990; FRI-UW-9005.

Williams, G.D., W.H. Pearson, N.R. Evans, and M.G. Anderson. 2004. Benson Beach demonstration project: Composition and abundance of biota at three alternative sump sites. PNNL-14522. Prepared for the U.S. Army Corps of Engineers, Portland District, by Battelle Marine Sciences Laboratory, Sequim, Washington. Published by Pacific Northwest National Laboratory, Richland, Washington. 


\subsection{FIGURES}

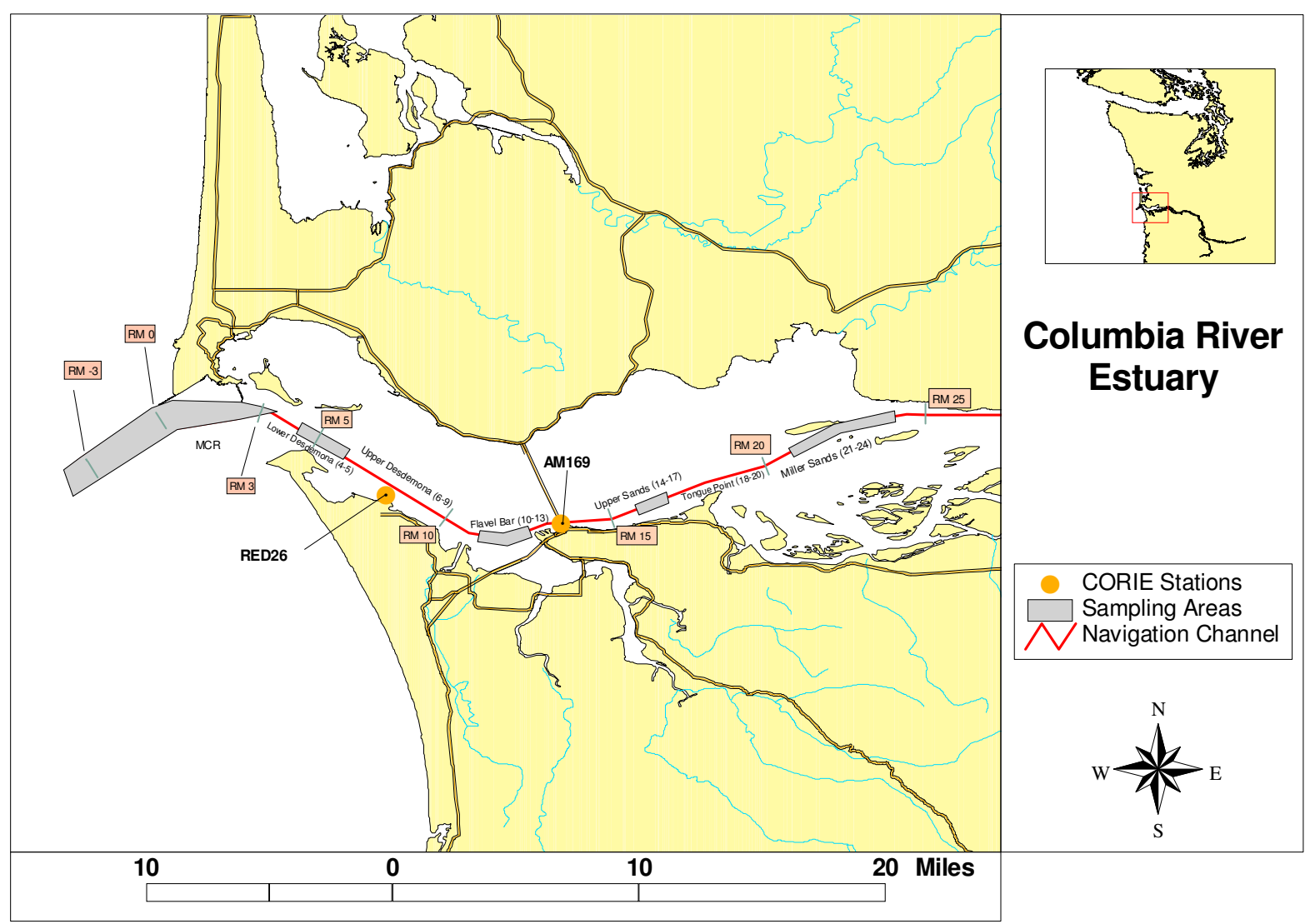

Figure 1. Map of Study Area, Summer 2002, 2004. 


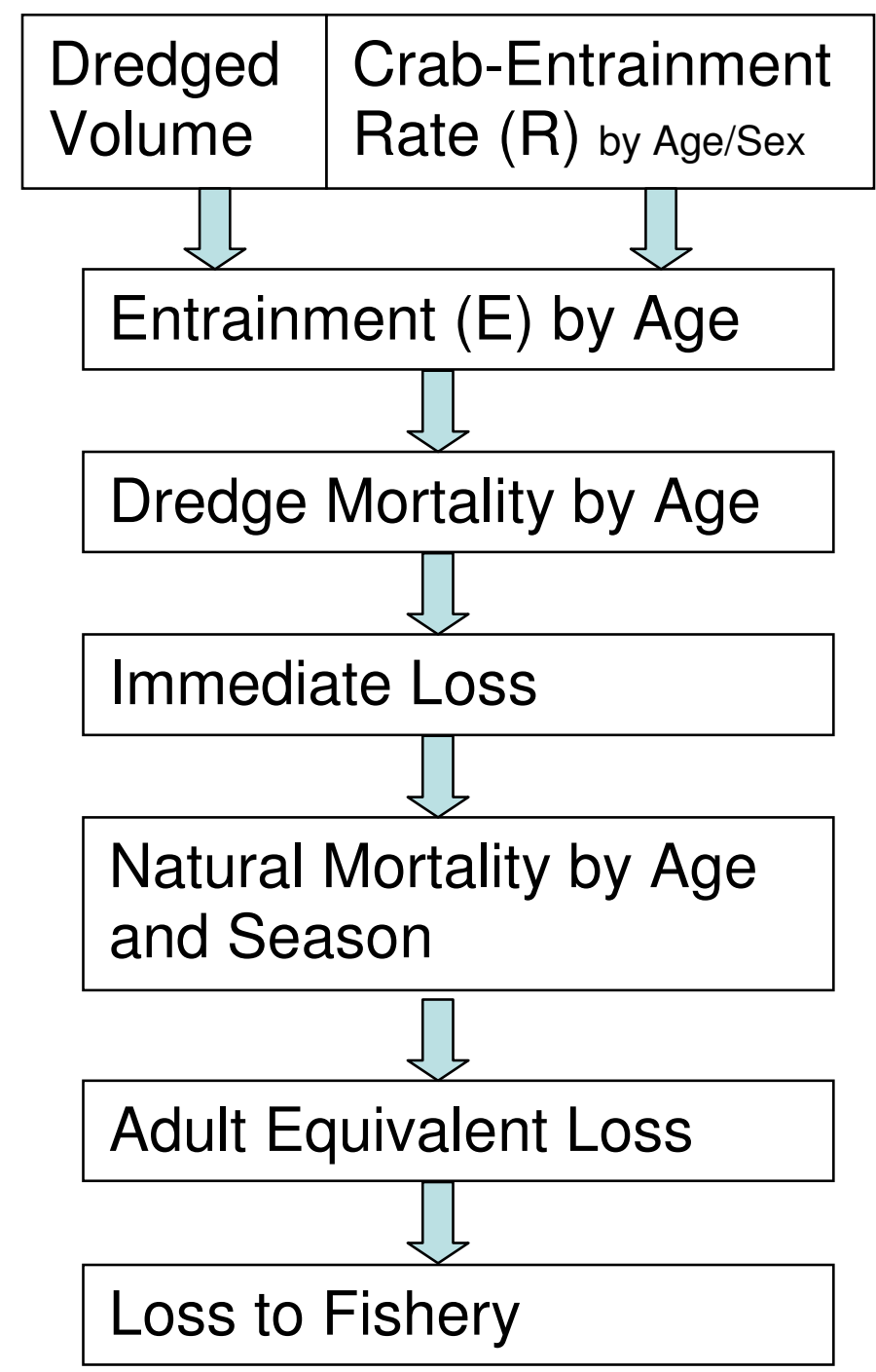

Figure 2. The Structure of a Modified Model for Estimating Dredging-Entrainment Impacts on Dungeness Crab (Modified from Armstrong et al. 1987) 


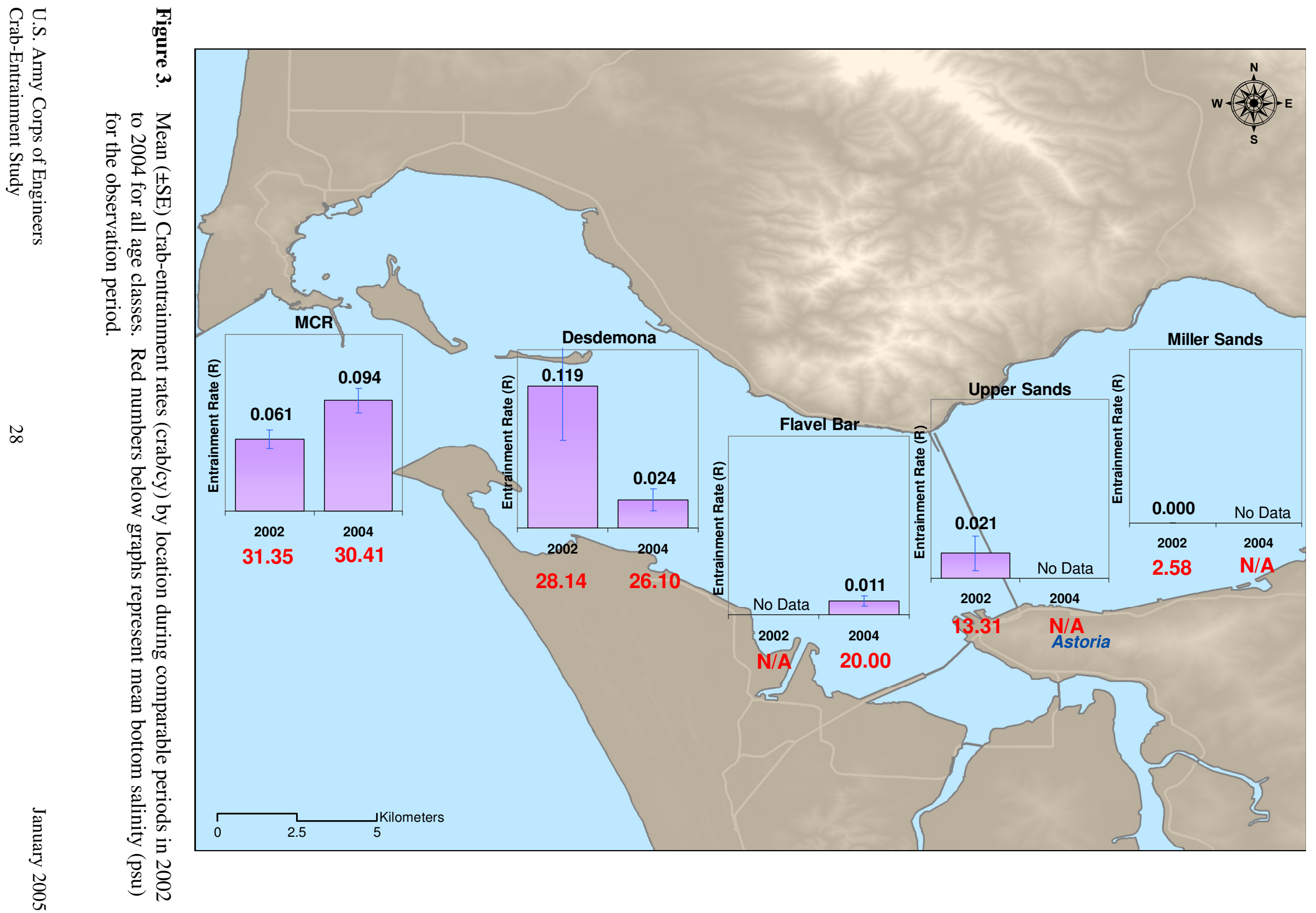





Figure 4. Mean $( \pm$ SE) entrainment rates (see Table 6) of Dungeness Crab in 2002 and 2004 by age class, at Desdemona Shoals and the Mouth of the Columbia River (2004 Flavel Bar values shown for comparison). 

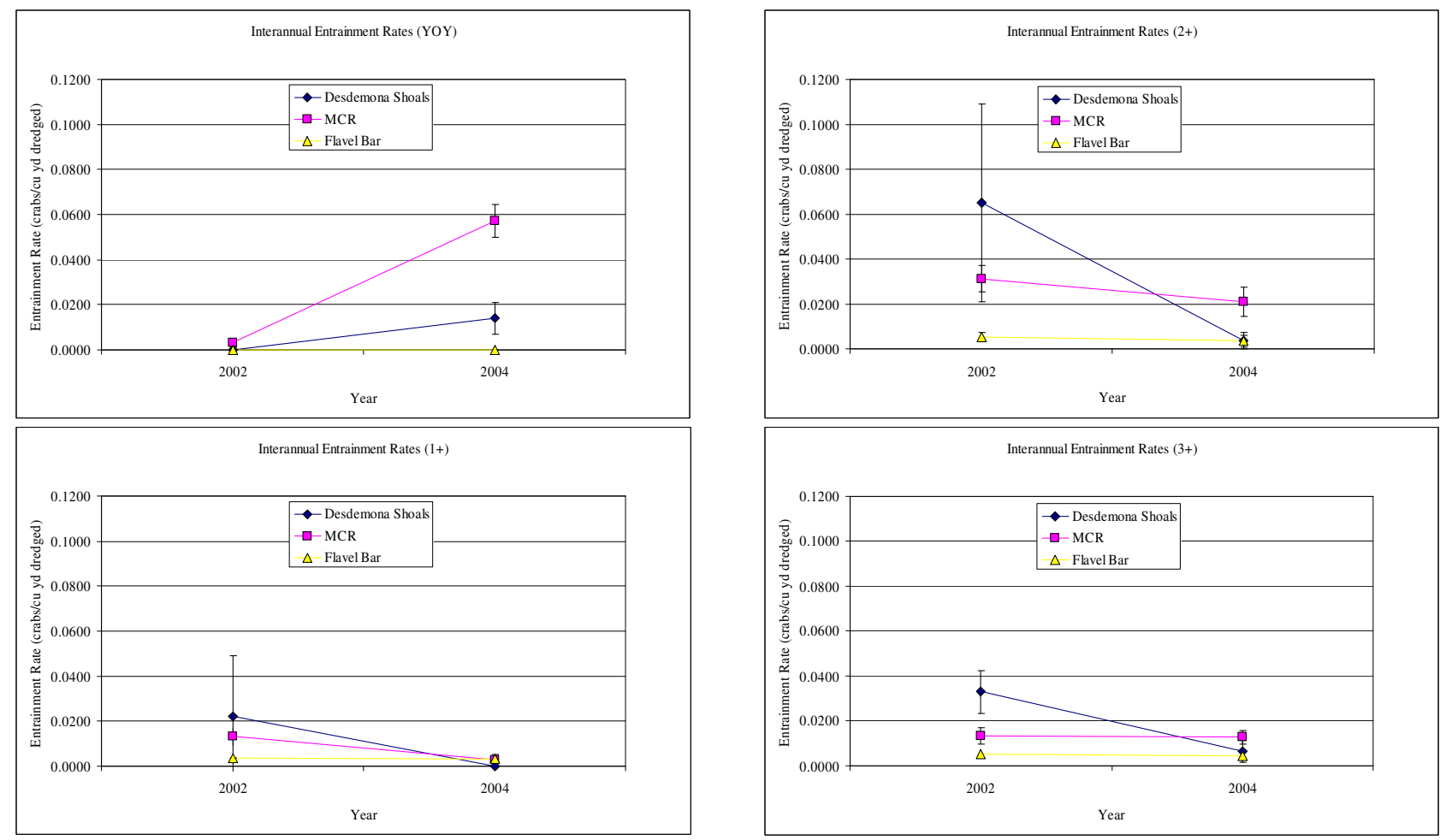

Figure 5. Mean ( \pm SE) entrainment rates of Dungeness Crab by age class in 2002 and 2004 at the Mouth of the Columbia River, Desdemona Shoals, and Flavel Bar (2002 Flavel Bar values based on weighted estimation). 


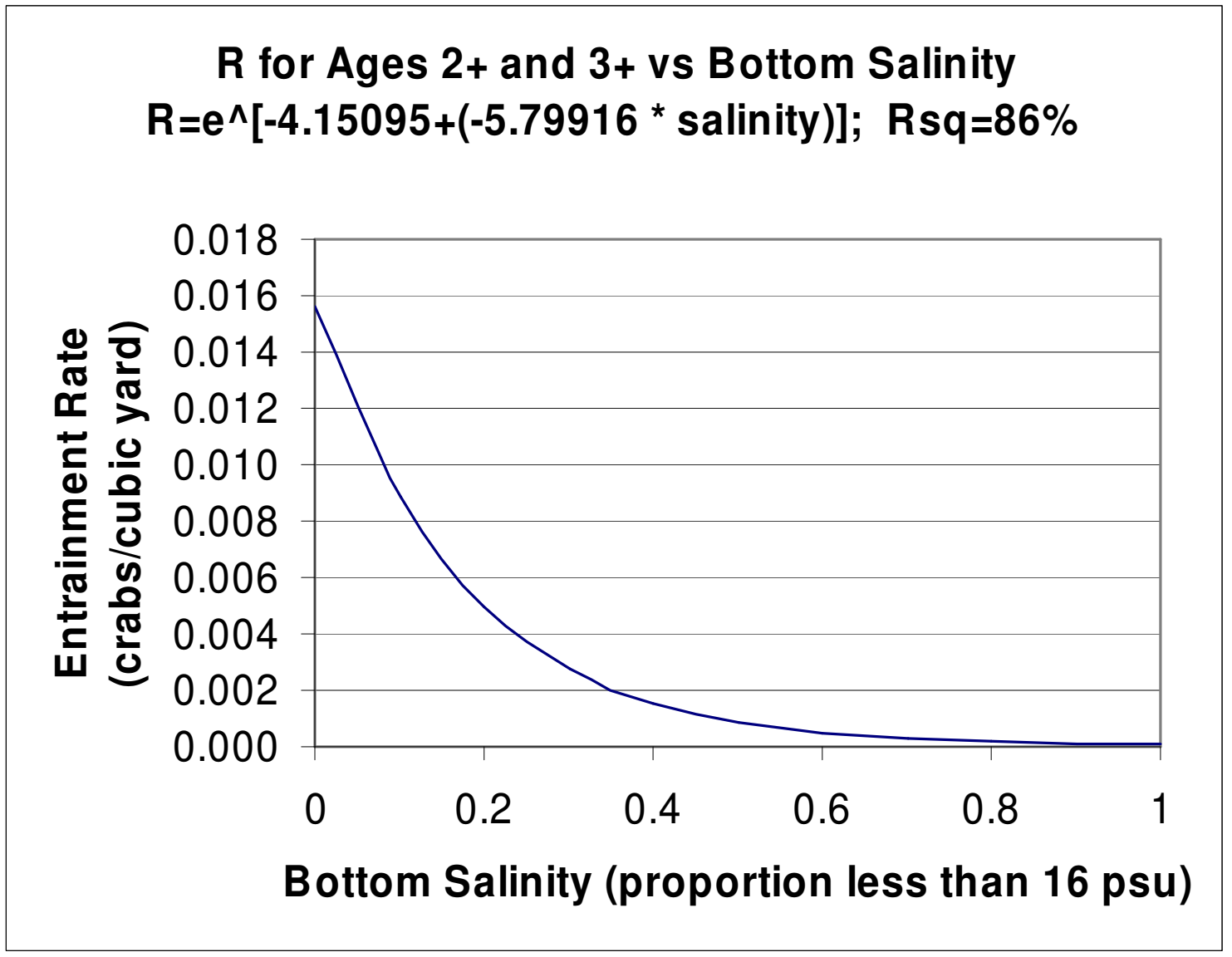

Figure 6. The relationship of entrainment rate ( $\mathrm{R}$ as crab/cy) to bottom salinity (as proportion of salinity observations less than 16 psu) using 2002 and 2004 data. 


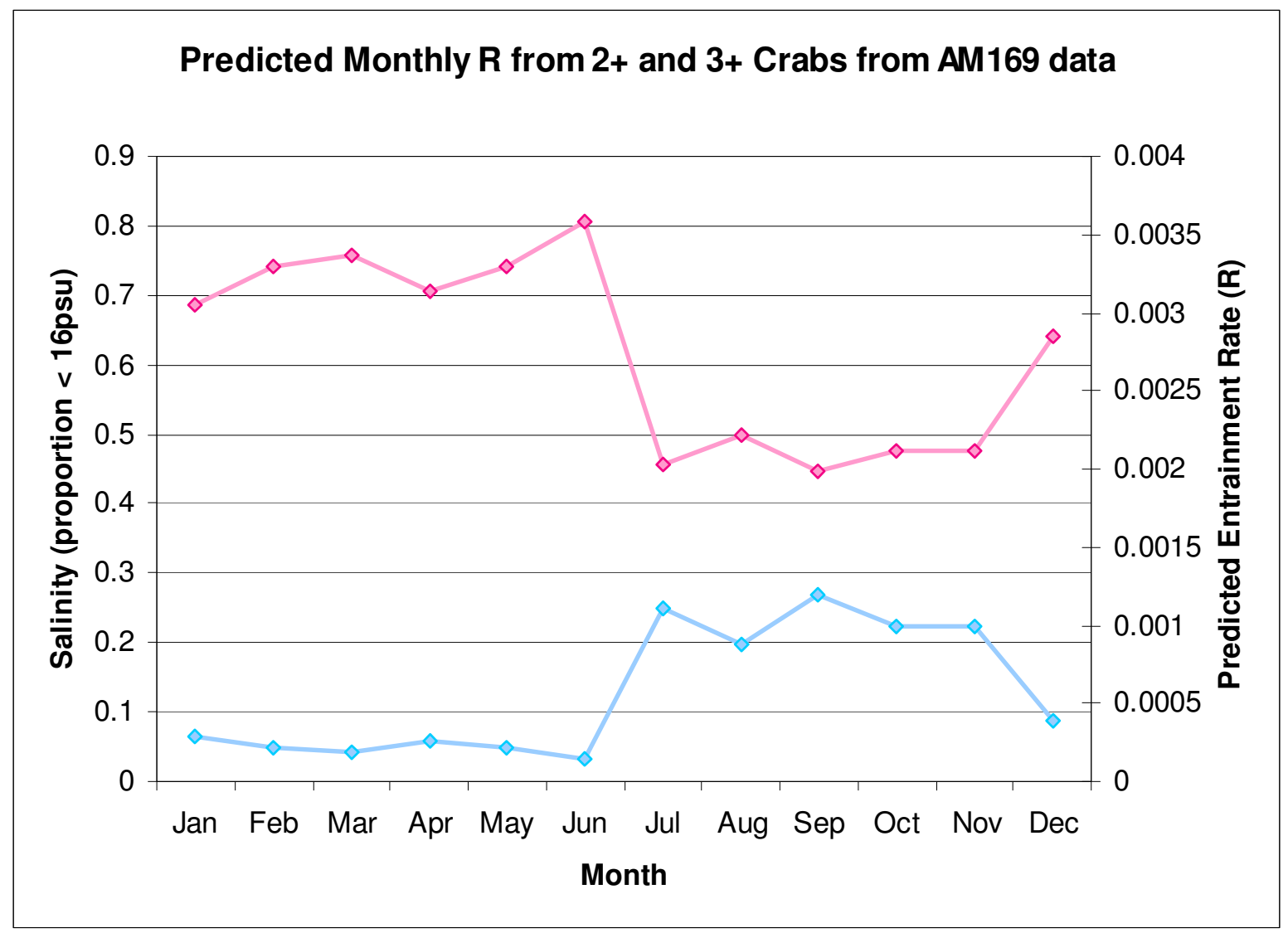

Figure 7. Predicted monthly entrainment rates $(\mathrm{R})$ of age $2+$ or age $3+$ crab using bottom salinity data from CORIE Station AM169. 


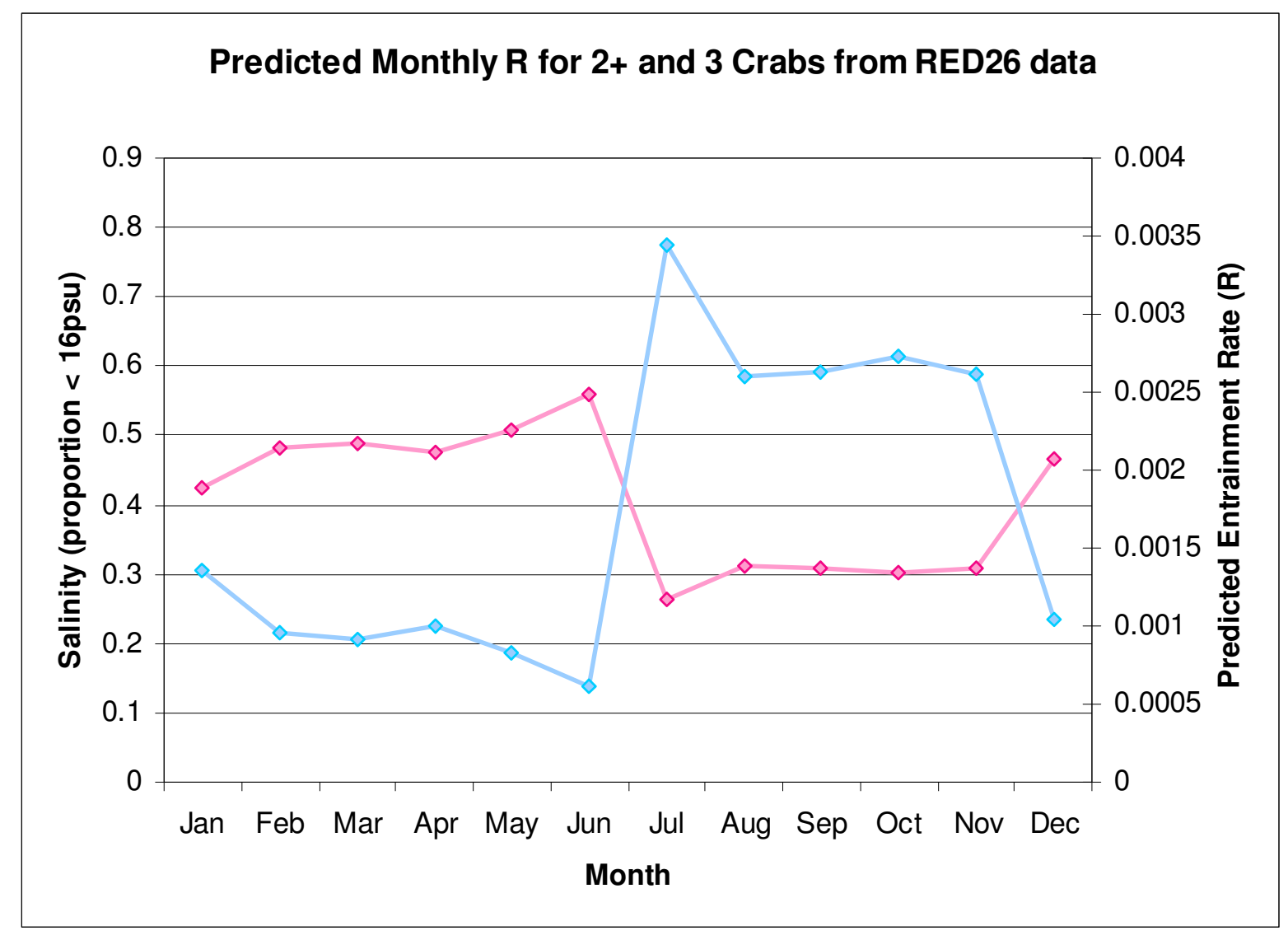

Figure 8. Predicted monthly entrainment rates $(\mathrm{R})$ of age $2+$ or age $3+$ crab using bottom salinity data from CORIE Station RED26. 


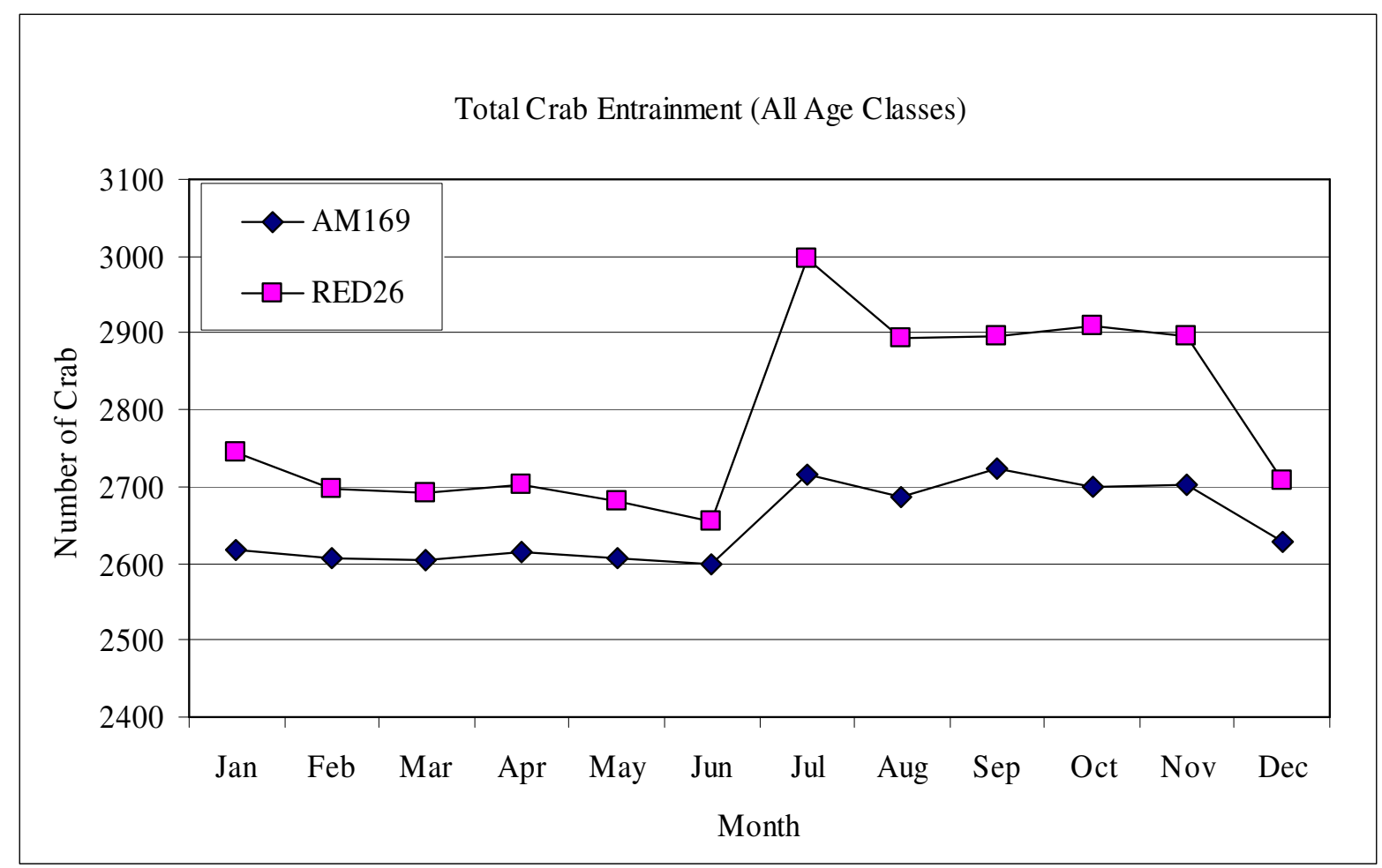

Figure 9. Predicted total daily entrainment (E) of crab (all age classes) by month at CORIE Stations AM169 and RED26 based on salinity model regressions and assuming a dredging volume of $60,000 \mathrm{cy}$. 


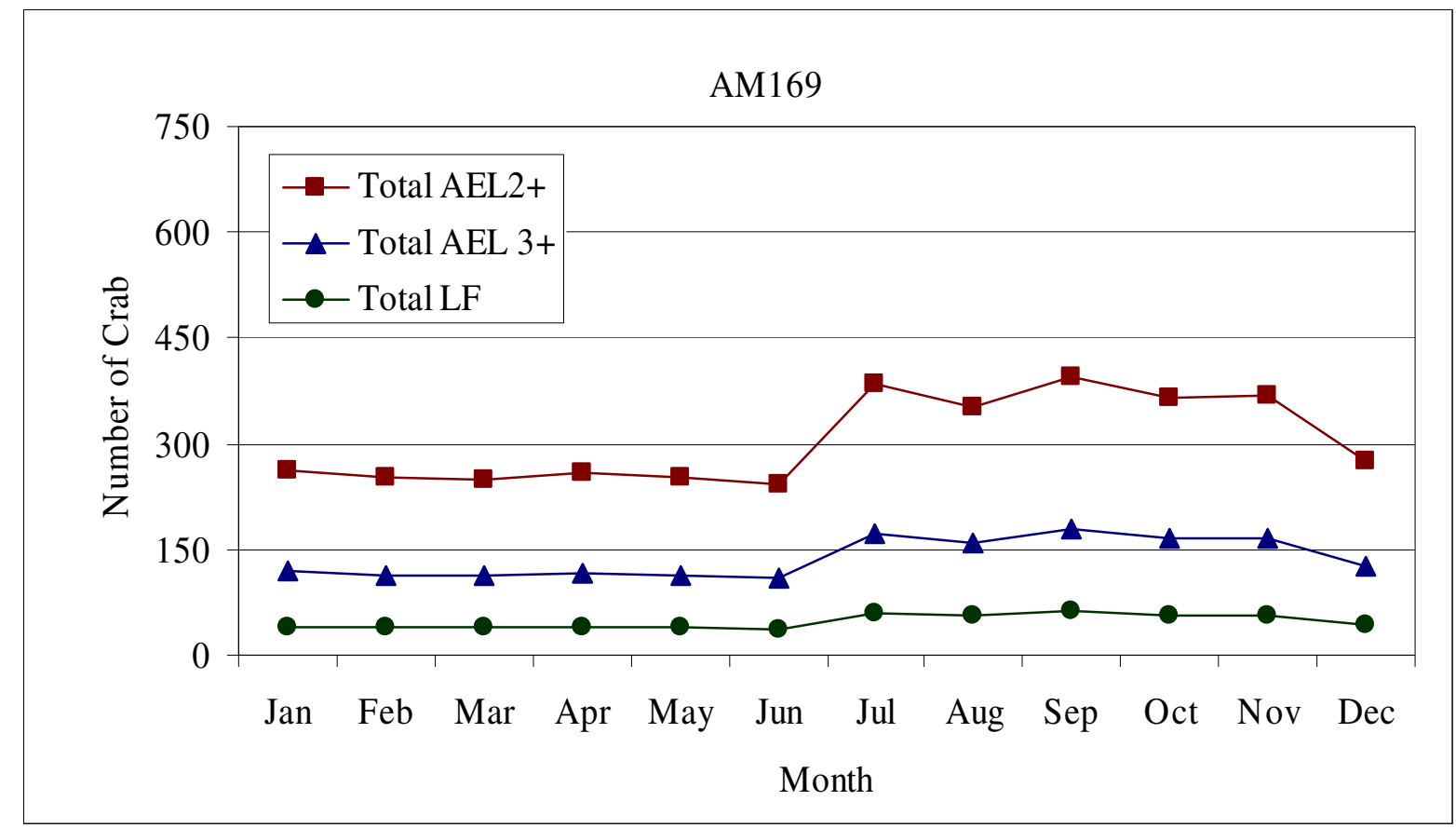

Figure 10. Projected daily (assuming 60,000 cy dredged/day) crab adult equivalent loss at ages $2+$ and $3+$ and loss to fishery, by month, based on bottom salinity data from CORIE Station AM169.

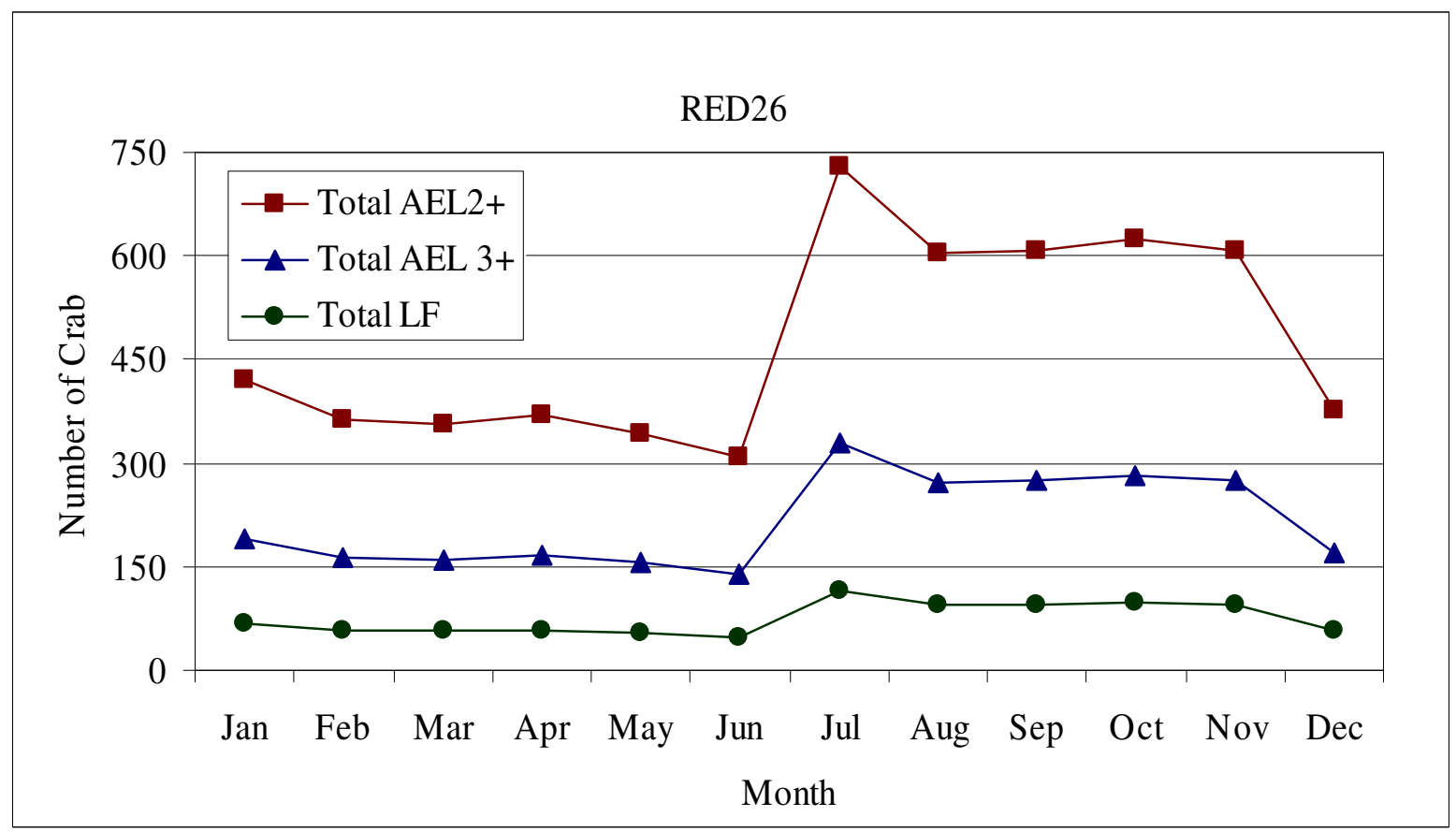

Figure 11. Projected daily (assuming 60,000 cy dredged/day) crab adult equivalent loss at ages $2+$ and $3+$ and loss to fishery based on bottom salinity data by month from CORIE Station RED26. 


\subsection{TABLES}

Table 1. Projected precision (CV) for Flavel Bar entrainment rates in 2002, based on sampling effort at the mouth of the Columbia River in 2004.

\begin{tabular}{|c|c|}
\hline $\begin{array}{c}\text { Number of Loads }(n) \text { at } \\
\text { the Mouth of the } \\
\text { Columbia River }\end{array}$ & $\operatorname{CV}\left(\widehat{\mathrm{FB}}_{02}\right) \times 100 \%$ \\
\hline 10 & $27.4 \%$ \\
\hline 20 & $20.1 \%$ \\
\hline 30 & $17.0 \%$ \\
\hline 40 & $15.2 \%$ \\
\hline 50 & $14.0 \%$ \\
\hline 60 & $13.1 \%$ \\
\hline 70 & $12.5 \%$ \\
\hline 80 & $12.0 \%$ \\
\hline
\end{tabular}


Table 2. Crab Entrainment Sampling Effort by Location during 2002 and 2004.

\begin{tabular}{|c|c|c|c|c|c|c|}
\hline Location & River Mile & Dates (2002) & $\begin{array}{c}\text { Total } \\
\text { Dredged } \\
\text { Volume } \\
\text { (cy) }\end{array}$ & $\begin{array}{c}\text { Total } \\
\text { Loads } \\
\text { Dredged } \\
\end{array}$ & $\begin{array}{c}\text { Total } \\
\text { Loads } \\
\text { Sampled } \\
\end{array}$ & $\begin{array}{c}\text { Total } \\
\text { Basket } \\
\text { Samples } \\
\end{array}$ \\
\hline Miller Sands & +21 to 24 & $1-10$ OCT & 443,563 & 75 & 36 & 140 \\
\hline Upper Sands & +14 to 17 & 23 SEPT & 54,036 & 9 & 9 & 27 \\
\hline Desdemona - 1 & +4 to +6 & 11-16 JUN & 186,737 & 33 & 17 & 169 \\
\hline Desdemona - 2 & +4 to +6 & 17 SEPT & 30,012 & 6 & 4 & 12 \\
\hline 2002 MCR - 1 & -2 to +2 & 9 to $21 \mathrm{JUL}$ & 563,024 & 101 & 47 & 142 \\
\hline 2002 MCR - 2 & +1 to +2 & 23 to $31 \mathrm{JUL}$ & 498,841 & 85 & 40 & 120 \\
\hline 2002 MCR - 3 & +1 to +2 & 24 AUG to $16 \mathrm{SEP}$ & $1,208,404$ & 212 & 85 & 255 \\
\hline 2002 MCR - 4 & -1 to +1 & 18 to $22 \mathrm{SEP}$ & 255,395 & 46 & 22 & 66 \\
\hline 2002 MCR - 5 & -2 to 0 & 8 to 9 OCT & 34,360 & 7 & 3 & 9 \\
\hline 2002 MCR - 6 & +1 to +2 & 9 to 13 OCT & 203,095 & 38 & 17 & 51 \\
\hline Total MCR 2002 & -2 to +2 & $9 \mathrm{JUL}$ to $13 \mathrm{OCT}$ & $2,763,119$ & 489 & 214 & 643 \\
\hline \multirow[t]{2}{*}{2002 Total } & +21 to -2 & $11 \mathrm{JUN}$ to $13 \mathrm{OCT}$ & $3,477,467$ & 612 & 280 & 991 \\
\hline & & Dates (2004) & & & & \\
\hline Flavel Bar & +10 to 13 & 17-20 AUG & 167,729 & 30 & 30 & 88 \\
\hline Desdemona & +4 to +6 & 20-24 AUG & 100,239 & 18 & 18 & 54 \\
\hline 2004 MCR - 1 & -2 to +2 & 21-23 AUG & 84,966 & 15 & 15 & 45 \\
\hline 2004 MCR - 2 & -2 to +2 & 7-9 SEP & 79,790 & 15 & 15 & 45 \\
\hline 2004 MCR - 3 & -2 to +2 & 14-16 SEP & 70,397 & 13 & 13 & 38 \\
\hline Total MCR 2004 & -2 to +2 & $21 \mathrm{AUG}$ - $16 \mathrm{SEP}$ & 235,153 & 43 & 43 & 128 \\
\hline 2004 Total & -2 to +10 & 17 AUG to 16 SEP & 503,121 & 91 & 91 & 270 \\
\hline
\end{tabular}

Note: Highlighted Rows Represent Data Used in Estimating 2002 Entrainment Rates for Flavel Bar. 
Table 3. Summary of Bottom Salinity and Total Number of Dungeness Crab (by Age Class), Crangon Shrimp, and Razor Clams Collected in Samples at Each Field Location in 2004.

\begin{tabular}{|l|r|r|r|r|r|r|r|r|r|r|}
\hline \multicolumn{1}{|c|}{ Location } & \multirow{2}{*}{ Loads } & \multicolumn{4}{|c|}{ Salinity (psu) } & \multicolumn{3}{c|}{ Dungeness Crab } & $\begin{array}{c}\text { Razor } \\
\text { Clams }\end{array}$ & $\begin{array}{c}\text { Crangon } \\
\text { Shrimp }\end{array}$ \\
\hline & (n) & Avg & Min & Max & YOY & Age 1+ & Age 2+ & Age 3+ & & \\
\hline Flavel Bar & 30 & 20.0 & 8.1 & 28.5 & 0 & 2 & 2 & 3 & 0 & 32 \\
\hline Desdemona Shoals & 18 & 26.1 & 14.3 & 31.3 & 4 & 0 & 1 & 2 & 0 & 8 \\
\hline MCR 1 & 15 & 30.7 & 23.9 & 33.3 & 23 & 1 & 8 & 9 & 1 & 351 \\
\hline MCR 2 & 15 & 32.4 & 30.6 & 33.3 & 20 & 1 & 13 & 6 & 46 & 593 \\
\hline MCR 3 & 13 & 27.7 & 21.5 & 30.6 & 35 & 2 & 6 & 3 & 2 & 255 \\
\hline & & & & & & & & & & \\
\hline MCR Total & 43 & & & & 78 & 4 & 27 & 18 & 49 & 1199 \\
\hline & & & & & & & & & & \\
\hline All Areas & 91 & & & & 82 & 6 & 30 & 23 & 50 & 1239 \\
\hline
\end{tabular}

Table 4. 2004 Entrainment Rates (R) (crab/cy) by Crab Age Class.

\begin{tabular}{|l|c|c|c|c|c|}
\hline \multicolumn{5}{|c|}{ Age Class } \\
\hline Year - Location & Age 0+ & Age 1+ & Age 2+ & Age 3+ & All \\
\hline 2004 Flavel Bar & 0.0000 & 0.0031 & 0.0035 & 0.0046 & 0.0112 \\
\hline 2004 Desdemona & 0.0139 & 0.0000 & 0.0035 & 0.0065 & 0.0239 \\
\hline 2004 MCR - 1 & 0.0535 & 0.0023 & 0.0147 & 0.0179 & 0.0883 \\
\hline 2004 MCR - 2 & 0.0445 & 0.0022 & 0.0341 & 0.0126 & 0.0934 \\
\hline 2004 MCR - 3 & 0.0760 & 0.0042 & 0.0137 & 0.0067 & 0.1007 \\
\hline 2004 MCR All & 0.0572 & 0.0028 & 0.0210 & 0.0128 & 0.0937 \\
\hline
\end{tabular}


Table 5. 2002 Entrainment Rates (R) (crab/cy) by Crab Age Class (From Pearson et al. 2002; 2003).

\begin{tabular}{|l|c|c|c|c|c|}
\hline & \multicolumn{5}{|c|}{ Age Class } \\
\hline Year - Location & Age 0+ & Age 1+ & Age 2+ & Age 3+ & All \\
\hline 2002 Miller Sands & 0.0000 & 0.0000 & 0.0000 & 0.0000 & 0.0000 \\
\hline 2002 Upper Sands & 0.0100 & 0.0100 & 0.0000 & 0.0000 & 0.0210 \\
\hline 2002 Desdemona - 1 & 0.0050 & 0.1930 & 0.0240 & 0.0010 & 0.2240 \\
\hline 2002 Desdemona - 2 & 0.0000 & 0.0220 & 0.0650 & 0.0330 & 0.1190 \\
\hline 2002 MCR - 1 & 0.0022 & 0.0117 & 0.0408 & 0.0109 & 0.0656 \\
\hline 2002 MCR - 2 & 0.0024 & 0.0263 & 0.0194 & 0.0009 & 0.0490 \\
\hline 2002 MCR - 3 & 0.0031 & 0.0132 & 0.0313 & 0.0134 & 0.0609 \\
\hline 2002 MCR - 4 & 0.0028 & 0.0091 & 0.0274 & 0.0137 & 0.0530 \\
\hline 2002 MCR - 5 & 0.0741 & 0.0000 & 0.0649 & 0.0399 & 0.1789 \\
\hline 2002 MCR - 6 & 0.0000 & 0.0075 & 0.0462 & 0.0080 & 0.0617 \\
\hline 2002 MCR All & 0.0033 & 0.0144 & 0.0322 & 0.0104 & 0.0603 \\
\hline
\end{tabular}

Table 6. Entrainment-Rate Data Used for Estimation of Flavel Bar 2002 Entrainment Rates

\begin{tabular}{|l|c|c|c|c|c|}
\hline & \multicolumn{5}{|c|}{ Age Class } \\
\hline Year - Location & Age 0+ & Age 1+ & Age 2+ & Age 3+ & All \\
\hline 2002 Flavel Bar & ND $^{(a)}$ & ND & ND & ND & ND \\
\hline 2002 Desdemona - 2 & 0.0000 & 0.0220 & 0.0650 & 0.0330 & 0.1190 \\
\hline 2002 MCR - 3 & 0.0031 & 0.0132 & 0.0313 & 0.0134 & 0.0609 \\
\hline & & & & & \\
\hline 2004 Flavel Bar & 0.0000 & 0.0031 & 0.0035 & 0.0046 & 0.0112 \\
\hline 2004 Desdemona & 0.0139 & 0.0000 & 0.0035 & 0.0065 & 0.0239 \\
\hline 2004 MCR All & 0.0572 & 0.0028 & 0.0210 & 0.0128 & 0.0937 \\
\hline
\end{tabular}

(a) $\mathrm{ND}=$ No Data.

Table 7. Site-Specific Ratio Estimator Table of 2002 Flavel Bar Entrainment Rates.

\begin{tabular}{|l|c|c|c|c|c|c|c|c|c|}
\hline & \multicolumn{3}{|c|}{$(\mathbf{R})$} & \multicolumn{4}{c|}{ S.E. } \\
\hline & Age 0+ & Age 1+ & Age 2+ & Age 3+ & & & & & \\
\hline $\begin{array}{l}\text { MCR data } \\
\text { Estimate }\end{array}$ & 0.0000 & 0.0146 & 0.0052 & 0.0048 & & 0.0000 & 0.0182 & 0.0057 & 0.0051 \\
\hline $\begin{array}{l}\text { Desdemona data } \\
\text { Estimate }\end{array}$ & 0.0000 & 0.0000 & 0.0650 & 0.0234 & & 0.0000 & 0.0000 & 0.1014 & 0.0300 \\
\hline & & & & & & & & & \\
\hline $\begin{array}{l}\text { Arithmetic } \\
\text { Average }\end{array}$ & 0.0000 & 0.0073 & 0.0351 & 0.0141 & & 0.0000 & 0.0103 & 0.0423 & 0.0131 \\
\hline Weighted Average & 0.0000 & 0.0037 & 0.0054 & 0.0053 & & 0.0000 & 0.0000 & 0.0017 & 0.0016 \\
\hline
\end{tabular}


Table 8. Projected Dredge Volumes for Future Construction Dredging (to $40 \mathrm{ft}$ and from $40 \mathrm{ft}$ to $43 \mathrm{ft}$ ) Associated with the Columbia River Channel Improvement Project (Pearson et al. 2002).

\begin{tabular}{|c|c|c|c|c|c|}
\hline \multicolumn{3}{|c|}{ Dredging to 40 ft } & \multicolumn{3}{c|}{ Dredging from 40 ft to 43 ft } \\
\hline River Mile & Location & Volume (cy) & River Mile & Location & Volume (cy) \\
\hline 4 & Lower Desdem. & 94,688 & 4 & Lower Desdem. & 222,412 \\
\hline 5 & & 196,724 & 5 & & 353,916 \\
\hline 6 & Upper Desdem & 66,193 & 6 & Upper Desdem & 0 \\
\hline 7 & & 1,039 & 7 & & 0 \\
\hline 8 & & 52,398 & 8 & & 8,742 \\
\hline 9 & & 62,851 & 9 & & 8,742 \\
\hline 10 & Flavel Bar & 329,296 & 10 & & 298,732 \\
\hline 11 & & 535,074 & 11 & & 121,292 \\
\hline 12 & & 239,608 & 12 & & 72,425 \\
\hline 13 & & 65,743 & 13 & & 54,585 \\
\hline 14 & Upper Sands & 171,432 & 14 & Upper Sands & 51,945 \\
\hline 15 & & 271,842 & 15 & & 47,557 \\
\hline 16 & & 306,717 & 16 & & 0 \\
\hline 17 & & 108,631 & 17 & & 14,775 \\
\hline 18 & Tongue Point & 174,113 & 18 & Tongue Point & 6,976 \\
\hline 19 & & 162,864 & 19 & & 13,283 \\
\hline 20 & & 127,219 & 20 & & $1,325,282$ \\
\hline Total & & $2,966,432$ & Total & & \\
\hline
\end{tabular}

Table 9. Summary of Projected Dredged Materials Volumes (cy) by Location for Future Construction Scenarios in River (from Pearson et al. 2002).

\begin{tabular}{|l|r|r|r|r|}
\hline \multicolumn{1}{|c|}{ Location } & River Miles & \multicolumn{1}{c|}{ To 40 ft } & \multicolumn{1}{c|}{$\begin{array}{c}\text { From 40 ft to } \\
\mathbf{4 3} \mathbf{~ t t}\end{array}$} & \multicolumn{1}{c|}{ Combined } \\
\hline Desdemona Shoals & +4 to +9 & 473,893 & 593,812 & $1,067,705$ \\
\hline Flavel Bar & +10 to +13 & $1,169,721$ & 542,349 & $1,712,070$ \\
\hline Upper Sands & +14 to +17 & 858,622 & 154,087 & $1,012,709$ \\
\hline Tongue Pt & +18 to +20 & 464,196 & 35,034 & 499,230 \\
\hline
\end{tabular}


Table 10. Crab Adult Equivalent Loss (Ages 2+ and 3+) and Loss to Male Fishery Projected for Construction Dredging to $40 \mathrm{ft}$.

\begin{tabular}{|c|c|c|c|c|c|c|}
\hline & & & AEL & $95 \% \mathrm{CI}$ & $\begin{array}{l}\text { Loss to } \\
\text { Fishery }\end{array}$ & $95 \%$ CI \\
\hline Location & Age Class & Sex & Total & & Total & \\
\hline \multirow[t]{2}{*}{ Desdemona } & $2+$ & $\mathrm{M}$ & 29909 & 11871 & 9422 & 3739 \\
\hline & & $\mathrm{F}$ & 29909 & 11871 & & \\
\hline \multirow[t]{2}{*}{ Flavel Bar! } & $2+$ & $M$ & 3682 & 3755 & 1160 & 1183 \\
\hline & & $\mathrm{F}$ & 3682 & 3755 & & \\
\hline \multirow[t]{2}{*}{ Upper Sands } & $2+$ & $\mathrm{M}$ & 77 & 148 & 24 & 46 \\
\hline & & $\mathrm{F}$ & 77 & 148 & & \\
\hline \multirow[t]{2}{*}{ Tongue Pt!! } & $2+$ & $M$ & 17 & 34 & 6 & 11 \\
\hline & & $\mathrm{F}$ & 17 & 34 & & \\
\hline sum & & $M \& F$ & 67370 & 31616 & 10612 & 4979 \\
\hline \multirow[t]{2}{*}{ Desdemona } & $3+$ & $M$ & 13459 & 5342 & 9422 & 3739 \\
\hline & & $\mathrm{F}$ & 13459 & 5342 & & \\
\hline \multirow[t]{2}{*}{ Flavel Bar! } & $3+$ & $\mathrm{M}$ & 1657 & 1690 & 1160 & 1183 \\
\hline & & $\mathrm{F}$ & 1657 & 1690 & & \\
\hline \multirow[t]{2}{*}{ Upper Sands } & $3+$ & $M$ & 34 & 66 & 24 & 46 \\
\hline & & $\mathrm{F}$ & 34 & 66 & & \\
\hline \multirow[t]{2}{*}{ Tongue Pt!! } & $3+$ & $M$ & 8 & 15 & 6 & 11 \\
\hline & & $\mathrm{F}$ & 8 & 15 & & \\
\hline sum & & $M \& F$ & 30316 & 14226 & 10612 & 4979 \\
\hline
\end{tabular}


Table 11. Crab Adult Equivalent Loss (Ages 2+ and 3+) and Loss to Male Fishery Projected for Construction Dredging from $40 \mathrm{ft}$ to $43 \mathrm{ft}$.

\begin{tabular}{|c|c|c|c|c|c|c|}
\hline & & & AEL & $95 \% \mathrm{CI}$ & $\begin{array}{l}\text { Loss to } \\
\text { Fishery }\end{array}$ & $95 \%$ CI \\
\hline Location & Age Class & Sex & Total & & Total & \\
\hline \multirow[t]{2}{*}{ Desdemona } & $2+$ & $\mathrm{M}$ & 23869 & 9474 & 7519 & 2984 \\
\hline & & $\mathrm{F}$ & 23869 & 9474 & & \\
\hline \multirow[t]{2}{*}{ Flavel Bar! } & $2+$ & $\mathrm{M}$ & 7942 & 8098 & 2502 & 2551 \\
\hline & & $\mathrm{F}$ & 7942 & 8098 & & \\
\hline \multirow[t]{2}{*}{ Upper Sands } & $2+$ & $\mathrm{M}$ & 427 & 822 & 134 & 259 \\
\hline & & $\mathrm{F}$ & 427 & 822 & & \\
\hline \multirow[t]{2}{*}{ Tongue Pt!! } & $2+$ & $M$ & 231 & 444 & 73 & 140 \\
\hline & & $\mathrm{F}$ & 231 & 444 & & \\
\hline sum & & $M \& F$ & 64938 & 37676 & 10228 & 5934 \\
\hline \multirow[t]{2}{*}{ Desdemona } & $3+$ & M & 10741 & 4263 & 7519 & 2984 \\
\hline & & $\mathrm{F}$ & 10741 & 4263 & & \\
\hline \multirow[t]{2}{*}{ Flavel Bar! } & $3+$ & $M$ & 3574 & 3644 & 2502 & 2551 \\
\hline & & $\mathrm{F}$ & 3574 & 3644 & & \\
\hline \multirow[t]{2}{*}{ Upper Sands } & $3+$ & $M$ & 192 & 370 & 134 & 259 \\
\hline & & $\mathrm{F}$ & 192 & 370 & & \\
\hline \multirow[t]{2}{*}{ Tongue Pt!! } & $3+$ & $M$ & 104 & 200 & 73 & 140 \\
\hline & & $\mathrm{F}$ & 104 & 200 & & \\
\hline sum & & $M \& F$ & 29222 & 16954 & 10228 & 5934 \\
\hline
\end{tabular}


Table 12. Summary of Adult Equivalent Loss at Ages 2+ and 3+, and Losses to Fishery for Construction Dredging with 95\% Confidence Limits.

\begin{tabular}{|c|c|c|c|c|c|c|}
\hline \multirow{2}{*}{$\begin{array}{c}\text { Project } \\
\text { Location }\end{array}$} & \multicolumn{2}{|c|}{ AEL at Age 2+ } & \multicolumn{2}{|c|}{ AEL at Age 3+ } & \multicolumn{2}{|c|}{ Loss to Fishery } \\
\hline & $\begin{array}{c}\text { Lower } 95 \% \\
\text { CL }\end{array}$ & $\begin{array}{c}\text { Upper } 95 \% \\
\text { CL }\end{array}$ & $\begin{array}{c}\text { Lower 95\% } \\
\text { CL }\end{array}$ & $\begin{array}{c}\text { Upper 95\% } \\
\text { CL }\end{array}$ & $\begin{array}{c}\text { Lower 95\% } \\
\text { CL }\end{array}$ & $\begin{array}{c}\text { Upper 95\% } \\
\text { CL }\end{array}$ \\
\hline \multicolumn{7}{|c|}{$\begin{array}{c}\text { Dredging to } 40 \\
\mathrm{ft}\end{array}$} \\
\hline Desdemona & 36,076 & 83,560 & 16,234 & 37,602 & 5,683 & 13,161 \\
\hline Flavel & 0 & 14,874 & 0 & 6,694 & 0 & 2,343 \\
\hline Upper Sands & 0 & 450 & 0 & 200 & 0 & 70 \\
\hline Tongue Point & 0 & 102 & 0 & 46 & 0 & 17 \\
\hline Total & 36,076 & 98,968 & 16,234 & 44,542 & 5,683 & 15,591 \\
\hline \multicolumn{7}{|c|}{$\begin{array}{c}\text { Dredging from } \\
40 \mathrm{ft} \text { to } 43 \mathrm{ft}\end{array}$} \\
\hline Desdemona & 28,790 & 66,686 & 12,956 & 30,008 & 4,535 & 10,503 \\
\hline Flavel & 0 & 32,080 & 0 & 14,436 & 0 & 5,053 \\
\hline Upper Sands & 0 & 2,498 & 0 & 1,124 & 0 & 393 \\
\hline Tongue Point & 0 & 1,350 & 0 & 608 & 0 & 213 \\
\hline Total & 28,790 & 102,614 & 12,956 & 46,176 & 4,535 & 16,162 \\
\hline $\begin{array}{l}\text { Combined } \\
\text { Scenarios } \\
\end{array}$ & 64,866 & 201,600 & 29,190 & 90,718 & 10,218 & $\mathbf{3 1 , 7 5 3}$ \\
\hline
\end{tabular}

Table 13. Results of Regressions Involving Entrainment Rate (R, as Crabs/cy) and Bottom Salinity (Proportion of Observations Below or Above a Given Salinity Value (psu).

\begin{tabular}{|c|c|c|c|c|c|c|}
\hline $\begin{array}{l}\text { Independent } \\
\text { Variable }\end{array}$ & Dependent variable & $\mathrm{N}$ & Significant & $\mathrm{p}$-value & $\begin{array}{c}\mathrm{R}- \\
\text { squared }\end{array}$ & Comments \\
\hline R All age classes & Proportion > $32 \mathrm{psu}$ & 7 & No & 0.36959 & 0.163 & \\
\hline R All age classes & Proportion $>28 \mathrm{psu}$ & 7 & Yes & 0.03180 & 0.635 & \\
\hline R All age classes & Proportion < $16 \mathrm{psu}$ & 7 & Yes & 0.01143 & 0.752 & $\begin{array}{r}\text { without June } 2002 \\
\text { Desdemona }\end{array}$ \\
\hline R All age classes & Proportion < $16 \mathrm{psu}$ & 8 & Yes & 0.02426 & 0.599 & $\begin{array}{r}\text { with June } 2002 \\
\text { Desdemona }\end{array}$ \\
\hline R Age 0+ & Proportion < $16 \mathrm{psu}$ & 7 & No & 0.44961 & 0.118 & \\
\hline R age $1+$ & Proportion < $16 \mathrm{psu}$ & 7 & No & 0.41847 & 0.134 & \\
\hline R Age 2+ & Proportion $<16 \mathrm{psu}$ & 7 & Yes & 0.00368 & 0.840 & \\
\hline R Age 3+ & Proportion < $16 \mathrm{psu}$ & 7 & Yes & 0.00108 & 0.901 & \\
\hline R Ages 2+ and 3+ & Proportion < $16 \mathrm{psu}$ & 14 & Yes & 0.0000014 & 0.866 & \\
\hline
\end{tabular}

Table 14. Monthly Availability of Bottom Salinity Data from CORIE Station AM169 during 20012003 (Shading Indicates Data Available).

\begin{tabular}{|l|l|l|l|l|l|l|l|l|l|l|l|l|}
\hline 2001 & & & & & & & & & & & & \\
\hline 2002 & & & & & & & & & & & & \\
\hline 2003 & & & & & & & & & & & & \\
\hline & Jan & Feb & Mar & Apr & May & Jun & Jul & Aug & Sep & Oct & Nov & Dec \\
\hline
\end{tabular}


Table 15. Monthly Availability of Bottom Salinity Data from CORIE Station RED26 during 2001-2003 (Shading Indicates Data Available).

\begin{tabular}{|l|l|l|l|l|l|l|l|l|l|l|l|l|}
\hline 2001 & & & & & & & & & & & & \\
\hline 2002 & & & & & & & & & & & & \\
\hline 2003 & & & & & & & & & & & & \\
\hline & Jan & Feb & Mar & Apr & May & Jun & Jul & Aug & Sep & Oct & Nov & Dec \\
\hline
\end{tabular}

Table 16. Monthly Predictions of Crab-Entrainment Rates (crab/cy) by Age Class at AM169.

\begin{tabular}{|l|r|r|r|r|r|}
\hline \multicolumn{1}{|c|}{ Month } & $\begin{array}{c}\text { Salinity: } \\
\text { Proportion } \\
\text { <16 psu }\end{array}$ & Age 0+ & Age 1+ & Age 2+ & Age 3+ \\
\hline Jan & 0.423 & 0.0049 & 0.0381 & 0.0003 & 0.0003 \\
\hline Feb & 0.482 & 0.0049 & 0.0381 & 0.0002 & 0.0002 \\
\hline Mar & 0.490 & 0.0049 & 0.0381 & 0.0002 & 0.0002 \\
\hline Apr & 0.474 & 0.0049 & 0.0381 & 0.0003 & 0.0003 \\
\hline May & 0.507 & 0.0049 & 0.0381 & 0.0002 & 0.0002 \\
\hline Jun & 0.561 & 0.0049 & 0.0381 & 0.0001 & 0.0001 \\
\hline Jul & 0.262 & 0.0049 & 0.0381 & 0.0011 & 0.0011 \\
\hline Aug & 0.310 & 0.0049 & 0.0381 & 0.0009 & 0.0009 \\
\hline Sep & 0.309 & 0.0049 & 0.0381 & 0.0012 & 0.0012 \\
\hline Oct & 0.302 & 0.0049 & 0.0381 & 0.0010 & 0.0010 \\
\hline Nov & 0.310 & 0.0049 & 0.0381 & 0.0010 & 0.0010 \\
\hline Dec & 0.467 & 0.0049 & 0.0381 & 0.0004 & 0.0004 \\
\hline
\end{tabular}

Note: Age $2+$ and age $3+$ rates derived from salinity regression equation $\mathrm{R}=\exp (-4.15095+(-5.79916 *$ salinity)); ages $0+$ and $1+$ rates based on mean values from all upriver sampling dates.

Table 17. Monthly Predictions of Crab-Entrainment Rates (crab/cy) by Age Class at RED26.

\begin{tabular}{|l|r|r|r|r|r|}
\hline \multicolumn{1}{|c|}{ Month } & $\begin{array}{c}\text { Salinity: } \\
\text { Proportion } \\
<\mathbf{1 6} \text { psu }\end{array}$ & Age 0+ & Age 1+ & \multicolumn{1}{c|}{ Age 2+ } & \multicolumn{1}{c|}{ Age 3+ } \\
\hline Jan & 0.687 & 0.0049 & 0.0381 & 0.0014 & 0.0014 \\
\hline Feb & 0.742 & 0.0049 & 0.0381 & 0.0010 & 0.0010 \\
\hline Mar & 0.758 & 0.0049 & 0.0381 & 0.0009 & 0.0009 \\
\hline Apr & 0.705 & 0.0049 & 0.0381 & 0.0010 & 0.0010 \\
\hline May & 0.741 & 0.0049 & 0.0381 & 0.0008 & 0.0008 \\
\hline Jun & 0.807 & 0.0049 & 0.0381 & 0.0006 & 0.0006 \\
\hline Jul & 0.457 & 0.0049 & 0.0381 & 0.0034 & 0.0034 \\
\hline Aug & 0.497 & 0.0049 & 0.0381 & 0.0026 & 0.0026 \\
\hline Sep & 0.445 & 0.0049 & 0.0381 & 0.0026 & 0.0026 \\
\hline Oct & 0.477 & 0.0049 & 0.0381 & 0.0027 & 0.0027 \\
\hline Nov & 0.476 & 0.0049 & 0.0381 & 0.0026 & 0.0026 \\
\hline Dec & 0.641 & 0.0049 & 0.0381 & 0.0010 & 0.0010 \\
\hline
\end{tabular}

Note: Age $2+$ and age $3+$ rates derived from salinity regression equation $\mathrm{R}=\exp (-4.15095+(-5.79916 *$ salinity $))$; ages $0+$ and $1+$ rates based on mean values from all upriver sampling dates. 
Table 18. Projected Daily Entrainment, AEL 2+, AEL 3+, and LF by Age Class and Month at AM169, Using Dredge Impact Model.

\begin{tabular}{|c|c|c|c|c|c|c|c|c|c|c|c|c|c|c|c|c|c|c|c|c|}
\hline & \multicolumn{5}{|c|}{$\mathbf{E}$} & \multicolumn{5}{|c|}{ AEL 2+ } & \multicolumn{5}{|c|}{ AEL 3+ } & \multicolumn{5}{|c|}{ LF } \\
\hline Month & 0+ & $1+$ & $2+$ & $3+$ & Total & 0+ & $1+$ & $2+$ & $3+$ & Total & 0+ & $1+$ & $2+$ & $3+$ & Total & $\mathbf{0 +}$ & $1+$ & $2+$ & $3+$ & Total \\
\hline Jan & 295.00 & 2287.00 & 17.55 & 17.55 & 2617.10 & 0.49 & 219.55 & 9.80 & 33.54 & 263.37 & 0.22 & 98.80 & 4.41 & 15.09 & 118.52 & 0.08 & 34.58 & 1.54 & 5.28 & 41.48 \\
\hline Feb & 295.00 & 2287.00 & 12.80 & 12.80 & 2607.59 & 0.49 & 219.55 & 7.14 & 24.45 & 251.63 & 0.22 & 98.80 & 3.21 & 11.00 & 113.23 & 0.08 & 34.58 & 1.12 & 3.85 & 39.63 \\
\hline Mar & 295.00 & 2287.00 & 11.65 & 11.65 & 2605.30 & 0.49 & 219.55 & 6.50 & 22.26 & 248.81 & 0.22 & 98.80 & 2.93 & 10.02 & 111.96 & 0.08 & 34.58 & 1.02 & 3.51 & 39.19 \\
\hline Apr & 295.00 & 2287.00 & 15.85 & 15.85 & 2613.70 & 0.49 & 219.55 & 8.85 & 30.29 & 259.17 & 0.22 & 98.80 & 3.98 & 13.63 & 116.63 & 0.08 & 34.58 & 1.39 & 4.77 & 40.82 \\
\hline May & 295.00 & 2287.00 & 12.87 & 12.87 & 2607.75 & 0.49 & 219.55 & 7.19 & 24.60 & 251.83 & 0.22 & 98.80 & 3.23 & 11.07 & 113.32 & 0.08 & 34.58 & 1.13 & 3.87 & 39.66 \\
\hline Jun & 295.00 & 2287.00 & 8.78 & 8.78 & 2599.56 & 0.49 & 219.55 & 4.90 & 16.77 & 241.71 & 0.22 & 98.80 & 2.20 & 7.55 & 108.77 & 0.08 & 34.58 & 0.77 & 2.64 & 38.07 \\
\hline Jul & 295.00 & 2287.00 & 66.73 & 66.73 & 2715.47 & 0.49 & 219.55 & 37.25 & 127.52 & 384.81 & 0.22 & 98.80 & 16.76 & 57.38 & 173.16 & 0.08 & 34.58 & 5.87 & 20.08 & 60.61 \\
\hline Aug & 295.00 & 2287.00 & 52.84 & 52.84 & 2687.68 & 0.49 & 219.55 & 29.49 & 100.97 & 350.50 & 0.22 & 98.80 & 13.27 & 45.44 & 157.72 & 0.08 & 34.58 & 4.64 & 15.90 & 55.20 \\
\hline Sep & 295.00 & 2287.00 & 71.35 & 71.35 & 2724.71 & 0.49 & 219.55 & 39.83 & 136.35 & 396.22 & 0.22 & 98.80 & 17.92 & 61.36 & 178.30 & 0.08 & 34.58 & 6.27 & 21.48 & 62.40 \\
\hline Oct & 295.00 & 2287.00 & 59.30 & 59.30 & 2700.60 & 0.49 & 219.55 & 33.10 & 113.31 & 366.45 & 0.22 & 98.80 & 14.89 & 50.99 & 164.90 & 0.08 & 34.58 & 5.21 & 17.85 & 57.72 \\
\hline Nov & 295.00 & 2287.00 & 59.84 & 59.84 & 2701.67 & 0.49 & 219.55 & 33.40 & 114.34 & 367.78 & 0.22 & 98.80 & 15.03 & 51.45 & 165.50 & 0.08 & 34.58 & 5.26 & 18.01 & 57.92 \\
\hline Dec & 295.00 & 2287.00 & 23.00 & 23.00 & 2628.01 & 0.49 & 219.55 & 12.84 & 43.96 & 276.83 & 0.22 & 98.80 & 5.78 & 19.78 & 124.58 & 0.08 & 34.58 & 2.02 & 6.92 & 43.60 \\
\hline
\end{tabular}

Table 19. Projected Daily Entrainment, AEL 2+, AEL 3+, and LF by Age Class and Month at RED26, Using Dredge Impact Model.

\begin{tabular}{|c|c|c|c|c|c|c|c|c|c|c|c|c|c|c|c|c|c|c|c|c|}
\hline & \multicolumn{5}{|c|}{$\mathbf{E}$} & \multicolumn{5}{|c|}{ AEL 2+ } & \multicolumn{5}{|c|}{ AEL 3+ } & \multicolumn{5}{|c|}{ LF } \\
\hline Month & $0+$ & $1+$ & $2+$ & $3+$ & Total & $0+$ & $1+$ & $2+$ & $3+$ & Total & $0+$ & $1+$ & $2+$ & $3+$ & Total & $0+$ & $1+$ & $2+$ & $3+$ & Total \\
\hline Jan & 295.00 & 2287.00 & 81.20 & 81.20 & 2744.40 & 0.49 & 219.55 & 45.32 & 155.17 & 420.53 & 0.22 & 98.80 & 20.39 & 69.83 & 189.24 & 0.08 & 34.58 & 7.14 & 24.44 & 66.23 \\
\hline Feb & 295.00 & 2287.00 & 57.72 & 57.72 & 2697.45 & 0.49 & 219.55 & 32.22 & 110.31 & 362.56 & 0.22 & 98.80 & 14.50 & 49.64 & 163.15 & 0.08 & 34.58 & 5.07 & 17.37 & 57.10 \\
\hline Mar & 295.00 & 2287.00 & 55.08 & 55.08 & 2692.16 & 0.49 & 219.55 & 30.74 & 105.26 & 356.04 & 0.22 & 98.80 & 13.83 & 47.37 & 160.22 & 0.08 & 34.58 & 4.84 & 16.58 & 56.08 \\
\hline Apr & 295.00 & 2287.00 & 60.41 & 60.41 & 2702.83 & 0.49 & 219.55 & 33.72 & 115.44 & 369.20 & 0.22 & 98.80 & 15.17 & 51.95 & 166.14 & 0.08 & 34.58 & 5.31 & 18.18 & 58.15 \\
\hline May & 295.00 & 2287.00 & 50.05 & 50.05 & 2682.09 & 0.49 & 219.55 & 27.93 & 95.63 & 343.61 & 0.22 & 98.80 & 12.57 & 43.04 & 154.62 & 0.08 & 34.58 & 4.40 & 15.06 & 54.12 \\
\hline Jun & 295.00 & 2287.00 & 36.55 & 36.55 & 2655.09 & 0.49 & 219.55 & 20.40 & 69.84 & 310.28 & 0.22 & 98.80 & 9.18 & 31.43 & 139.62 & 0.08 & 34.58 & 3.21 & 11.00 & 48.87 \\
\hline Jul & 295.00 & 2287.00 & 206.68 & 206.68 & 2995.37 & 0.49 & 219.55 & 115.36 & 394.95 & 730.35 & 0.22 & 98.80 & 51.91 & 177.73 & 328.66 & 0.08 & 34.58 & 18.17 & 62.21 & 115.03 \\
\hline Aug & 295.00 & 2287.00 & 156.17 & 156.17 & 2894.34 & 0.49 & 219.55 & 87.17 & 298.43 & 605.64 & 0.22 & 98.80 & 39.22 & 134.29 & 272.54 & 0.08 & 34.58 & 13.73 & 47.00 & 95.39 \\
\hline Sep & 295.00 & 2287.00 & 157.52 & 157.52 & 2897.04 & 0.49 & 219.55 & 87.92 & 301.01 & 608.97 & 0.22 & 98.80 & 39.56 & 135.46 & 274.04 & 0.08 & 34.58 & 13.85 & 47.41 & 95.91 \\
\hline Oct & 295.00 & 2287.00 & 164.01 & 164.01 & 2910.03 & 0.49 & 219.55 & 91.54 & 313.42 & 625.00 & 0.22 & 98.80 & 41.19 & 141.04 & 281.25 & 0.08 & 34.58 & 14.42 & 49.36 & 98.44 \\
\hline Nov & 295.00 & 2287.00 & 156.99 & 156.99 & 2895.99 & 0.49 & 219.55 & 87.62 & 300.00 & 607.66 & 0.22 & 98.80 & 39.43 & 135.00 & 273.45 & 0.08 & 34.58 & 13.80 & 47.25 & 95.71 \\
\hline Dec & 295.00 & 2287.00 & 62.88 & 62.88 & 2707.76 & 0.49 & 219.55 & 35.10 & 120.16 & 375.30 & 0.22 & 98.80 & 15.79 & 54.07 & 168.88 & 0.08 & 34.58 & 5.53 & 18.93 & 59.11 \\
\hline
\end{tabular}


PNNL-15021

\section{DISTRIBUTION}

No. of

Copies

OFFSITE

6 Kim Larson

U.S. Army Corps of Engineers

Portland District

Environmental Resources CENWP-PE-E

P.O. Box 2946

Portland, OR 97208-2946

$1 \quad$ John R. Skalski

University of Washington

Fisheries Department

1325 4th Ave., Suite 1820

Box 358218

Seattle, WA 98101-2509

\section{ONSITE}

1 Gregory D. Williams MSL

1 Walter H. Pearson MSL

1 Information Release K1-06 